Article

\title{
Implementation and Use of a Mechanical Cone Penetration Test Database for Liquefaction Hazard Assessment of the Coastal Area of the Tuscany Region
}

\author{
Stefano Stacul ${ }^{1, *} \mathbb{\oplus}$, Aurora Magalotti ${ }^{1}$, Massimo Baglione ${ }^{2}$, Claudia Meisina $^{3}(\mathbb{D}$ and \\ Diego Lo Presti ${ }^{1}$ (1) \\ 1 Department of Civil and Industrial Engineering, University of Pisa, 56122 Pisa, Italy; \\ aurora.magalotti@gmail.com (A.M.); d.lopresti@ing.unipi.it (D.L.P.) \\ 2 Ufficio Prevenzione Sismica Regione Toscana, 50129 Firenze, Italy; massimo.baglione@regione.toscana.it \\ 3 Department of Earth and Environmental Sciences, University of Pavia, 27100 Pavia, Italy; \\ claudia.meisina@unipv.it \\ * Correspondence: stefano.stacul@for.unipi.it
}

Received: 3 February 2020; Accepted: 31 March 2020; Published: 2 April 2020

\begin{abstract}
This paper describes the implementation and use of a mechanical cone penetration test (CPTm) database for the evaluation of the liquefaction potential in some areas of Tuscany. More specifically, the database contains 4500 CPTm covering an area of 1787 square $\mathrm{km}$ and mainly concerns some coastal areas of Tuscany. Available simplified liquefaction evaluation procedures (LEPs) are mainly based on piezocone CPT (CPTu) test results and not on CPTm. An early interest on developing LEPs with reference to CPTm became quite soon obsolete because of the widespread use of piezocone. Unfortunately, in Italy, the use of CPTm is very popular. After the 2012 seismic sequence of Emilia-Romagna, the use of CPTm for liquefaction risk analysis has seen a renewed interest, even though such a topic should require further studies. This paper shows an empirical approach for liquefaction triggering assessment by CPTm using existing LEPs, thus making possible the use of the developed CPTm database for the preliminary screening of the study area.
\end{abstract}

Keywords: liquefaction; liquefaction potential; liquefaction evaluation procedure; electrical cone penetration test; mechanical cone penetration test; piezocone; CPT; tuscany region

\section{Introduction}

Liquefaction occurs mainly in loose saturated sandy soils and is responsible for the total or partial loss of soil resistance [1]. Effects of liquefaction on the urban context can be summarized as follows:

- structures resting on a liquefied soil could suffer relevant differential settlements, tilting, or overturning;

- buried structures are subject to hydraulic heave;

- in free-field conditions, pore water pressure increase and ejecta of sand could damage lifeline systems and several infrastructures;

- instabilities of both natural and artificial slopes can be triggered.

Recent examples of these effects include damage produced during the Emilia-Romagna and Canterbury earthquakes [2-13].

Identification of liquefaction prone areas, therefore, has become an important task as national/regional authorities need to define recommendations for sustainable development, land use planning, mitigation of liquefaction, and ground improvement purposes. 
The technical literature is rich in contributions about liquefaction evaluation procedures (LEPs), and most of them are simplified empirical procedures [14-24].

LEPs enable one to determine the factor of safety against liquefaction $\left(\mathrm{FS}_{\mathrm{L}}\right)$ at each investigated depth of the soil profile. The $\mathrm{FS}_{\mathrm{L}}$ is inferred by the ratio between the cyclic resistance ratio (CRR) and the cyclic stress ratio (CSR), which represent the shear strength of the soil and the earthquake-induced shear stress, respectively. Sampling in sandy deposits is very difficult, time consuming, and costly. Therefore, CRR is inferred from in situ tests, typically Standard Penetration Test SPT [14,15,17], cone penetration test (CPT) $[18,19,22-26]$, shear wave velocity [27,28], self-boring pressuremeter test (SBPT) [29], and flat dilatometer test (DMT) [30,31]. The CSR, which represents the amplitude of the seismic demand, is generally assessed via simplified formulations defined in the LEPs.

Once $\mathrm{FS}_{\mathrm{L}}$ has been evaluated at different depths, an index assessing the effects of liquefaction in terms of damage severity at ground level should be selected and then used for defining liquefaction hazard maps.

The most commonly used severity indexes are the Liquefaction Potential Index (LPI) (Iwasaki et al. [32]) and the Liquefaction Severity Number (LSN) (Tonkin and Taylor [33]). A modification of the LPI was proposed by Sonmez [34]. Papathanassiou et al. [3] have suggested different thresholds for the LPI. The Papathanassiou et al. [3] suggestion is very interesting as it is based on the liquefaction phenomena that occurred during the 2012 Emilia-Romagna sequence. Moreover, specific threshold values of the liquefaction severity in terms of LPI or LSN for each considered LEP and soil characteristics were suggested in Maurer et al. [12]. In any case, the use of different criteria or thresholds or the definition of different thresholds makes sense only when facing a post-liquefaction situation. Therefore, we decided to remain with Iwasaki's [32] original criteria. The aim was a preliminary screening of the study area and the applicability of the considered LEPs and CPTm database.

In this work, the acronym CPTu indicates a static penetration test that has been carried out using a piezocone (i.e., tip resistance $q_{c}$, sleeve friction $f_{s}$, and pore pressure $u_{2}$ are measured every 1 or 2 $\mathrm{cm}$ of penetration). Additionally, the acronym CPTm indicates a static penetration test that has been carried out using a mechanical tip (also called Begemann-type tip in this paper), which provides $q_{c}$ and $f_{s}$ every $20 \mathrm{~cm}$ [35]. CPT-based LEPs were developed with reference to CPTu tests. However, in many countries, huge CPTm databases are available. Therefore, it has become important to develop specific procedures enhancing the liquefaction potential evaluation and soil profile reconstruction via existing CPTm databases.

CPTm in comparison to CPTu is affected by a lower resolution, as CPTm measurements $\left(q_{c}\right.$ and $\left.f_{s}\right)$ and CPTu measurements $\left(q_{c}, f_{s}\right.$, and $\left.u_{2}\right)$ are available every 20 and 2 (or 1$) \mathrm{cm}$, respectively. This results in difficulties, in the case of CPTm, in identifying very thin liquefiable layers as shown in $[22,23]$ and in Boulanger and DeJong [36]. Moreover, CPTu allows users to measure excess pore pressure during the cone penetration, which is relevant for evaluating the total tip resistance $\left(q_{t}\right)$ and improving the capability of correctly identifying the soil behavior type (SBT) [37]. It is also possible to identify the normalized soil behavior type (SBTn), which is especially recommended at greater depths $[35,38,39]$.

Because of the constructive details, the sleeve friction $\left(f_{s}\right)$ measured by using the Begemann cone $(\mathrm{CPTm})$ is systematically greater than that obtained with the piezocone (see, as an example, Lo Presti et al. [30]). As both $f_{s}$ and $q_{c}$ are used to identify the SBT (or SBTn), it is obvious that differences in terms of $f_{s}$ and $q_{c}$ could affect the assessment of the $\mathrm{FS}_{\mathrm{L}}$. On the other hand, while differences in terms of $f_{s}$ are measurable, those in terms of $q_{c}$ are quite negligible [40].

Finally, the interpretation of CPTm tests using the SBTn classification system [16,38] and its soil classification index $\left(I_{C}\right)$, which was developed with reference to $\mathrm{CPTu}$, tends to underestimate the grain size (for more details, see Section 4.3). Consequently, loose sands could be erroneously identified as silt mixtures [41-43], which in turn leads to an overestimation of the safety factor against liquefaction, $\mathrm{FS}_{\mathrm{L}}$. Indeed, the presence of fines leads to an increase in the soil resistance according to the available LEPs. 
In various countries, as in Italy, CPT tests are carried out with a mechanical tip. Therefore, CPTm results and CPT-based procedures require some corrections.

In this work, a CPTm database of the Tuscany region (Italy) was implemented and then used to assess the liquefaction hazard of this region's coastal area. The use of the developed database was possible by applying two recently proposed correction procedures (described in Section 4.3) to re-interpret CPTm results [41,42]. The first correction procedure is based on a correlation between $f_{s}$ measured with CPTm and that obtained from CPTu. Such a correlation was obtained by comparing some pairs of CPTu and CPTm that were carried out in the Pisa plain (Tuscany, Italy). In any case, it is worthwhile to remember that the considered stratigraphy involves both sand, clay, and silt mixture layers. The second correction procedure modifies $I_{C}$ as obtained from CPTm. The correction factor of the classification index $\left(\Delta I_{C}\right)$ is a function of the measured cone tip resistance $\left(q_{c}\right)$.

Such a correlation was obtained by using 78 pairs of CPTm and CPTu that were carried out in the urban areas of San Carlo, Mirabello, and Sant'Agostino, located in the Emilia-Romagna region (Italy) and hit by the 2012 Emilia-Romagna seismic sequence.

The same approach (i.e., the use of a correction factor of the classification index) was used in the case of dredged sediments and silt mixtures [43]. The Emilia-Romagna database and that of Tuscany mainly concern Holocene alluvial deposits of silt mixtures and sandy layers.

In Meisina et al. [41,42], the two correlations were applied to several pairs of CPTm and CPTu tests belonging to the database of the Emilia-Romagna region, which was concerned by the seismic sequence of May-June 2012 (Regione Emilia Romagna [44]), and to some pairs of CPTm and CPTu in a test site located in Pisa.

The above-mentioned papers qualitatively demonstrated the enhanced capability of the re-interpreted CPTm results in identifying the soil profile and the potentially liquefiable layers. Such an assessment of the effectiveness of the adopted correction procedures of CPTm was possible due to the availability of borehole logs and evidence of liquefaction. Moreover, the effectiveness of these correlations in improving the evaluation of the liquefaction severity indexes by CPTm was verified by comparing several pairs of CPTm and CPTu that were carried out in the Emilia-Romagna region. The comparison involved both sites in which liquefaction occurred and sites in which liquefaction did not occur. The predicted liquefaction hazard was consistent with liquefaction phenomena that were observed in 2012. In any case, because of the limited number of CPTu-CPTm pairs, a statistical comparison was not possible.

\section{Implementation of the CPT Database of the Tuscany Region}

In agreement with the technical staff of the Tuscany region, a plan was drawn up to collect the available CPTm and CPTu tests. The following databases were used:

- CPT test database from the Tuscany region (managed by the consortium LaMMA), and available on [45];

- CPT test database available from the seismic microzonation studies of the municipalities of the Tuscany region;

- CPT test database from the provinces of the Tuscany region.

Furthermore, the Tuscany region and the Department of Civil and Industrial Engineering of Pisa University have recovered further cone penetration tests from engineers and geologists working in this territory. However, it was not possible to find boreholes and undisturbed sampling close to each cone penetration test. Since the groundwater table (GWT) level was rarely available in the CPT test reports, the Tuscany region carried out an ad-hoc study to infer the water table depth from the piezometric surface, which was available for almost the entire study area. The latter was inferred by the phreatimetric studies carried out by the Basin Authorities of the Arno and Serchio rivers (Figure 1). It is important to stress that the water table depth in the whole study area was accurately identified. Indeed, water table is an important parameter. The considered values represent the average 
depth after considering the seasonal variations. Considering that the seismic risk in Italy is assessed by a probabilistic approach (NTC, 2018 [46]), the average value of the water table depth seems an acceptable assumption for a study covering an area of about 1800 square $\mathrm{km}$. Most of the CPT data were not in a digital format or on a digital support, thus it was necessary to digitize the collected data. The above-mentioned databases consisted of 5362 CPTs. It was possible to convert only 4500 CPTm and 16 CPTu to a digital format. These data represent the available geo-referenced database. Tables 1-3 summarize, for each macro-area in which the study territory was divided, the number of available CPT tests (CPTm and CPTu), and the maximum depth attained during the tests.

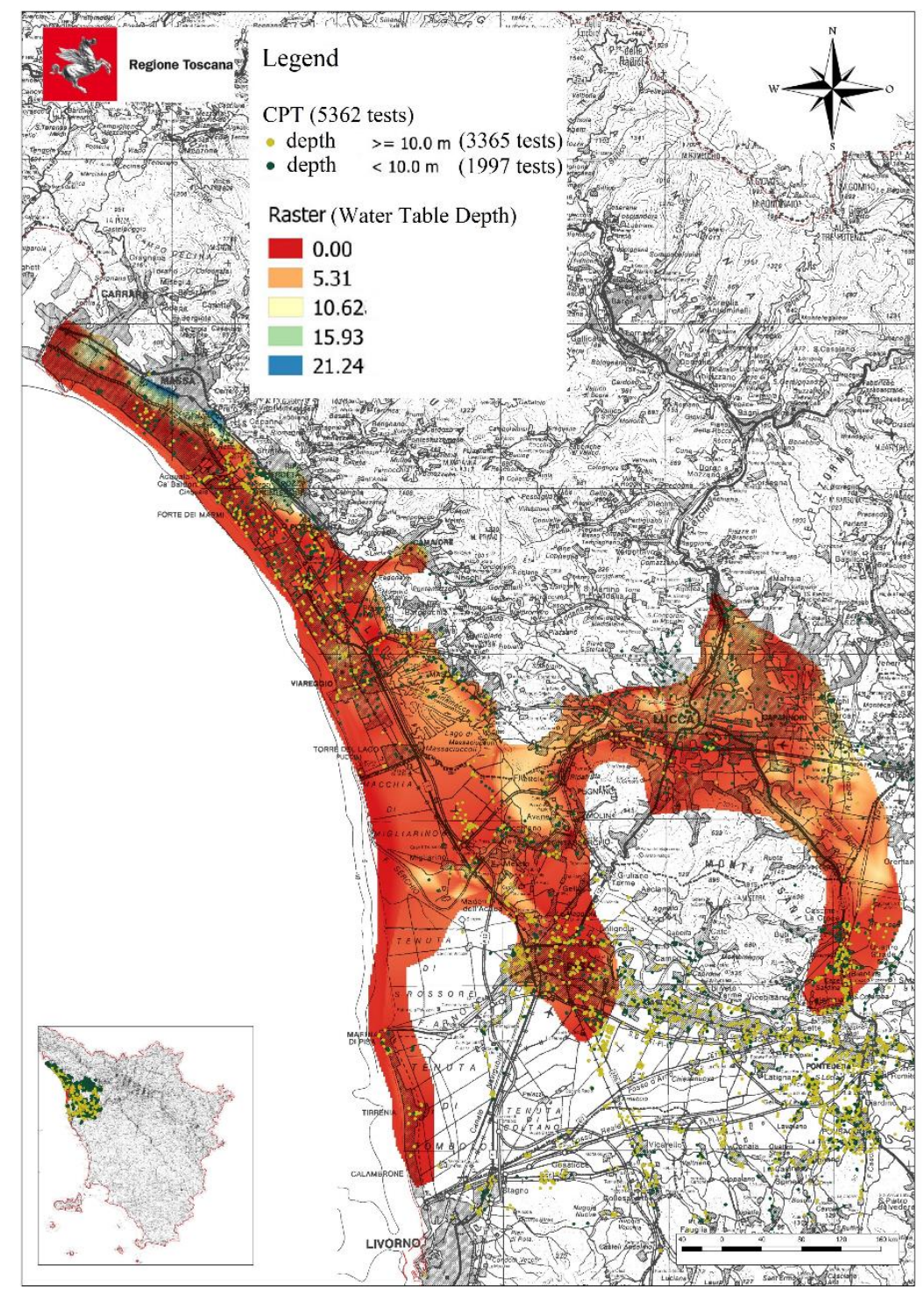

Figure 1. Map of the piezometric surface in the study area (estimated). 
Table 1. Cone penetration test (CPT) database for the macro-area of Versilia.

\begin{tabular}{|c|c|c|c|c|c|c|c|c|}
\hline Municipality & n CPTm & n CPTu & $0<\mathrm{z} \leq 5 \mathrm{~m}$ & $5<\mathrm{z} \leq 8 \mathrm{~m}$ & $8<\mathrm{z} \leq 10 \mathrm{~m}$ & $10<\mathrm{z} \leq 15 \mathrm{~m}$ & $15<\mathrm{z} \leq 20 \mathrm{~m}$ & $>20 \mathrm{~m}$ \\
\hline Camaiore & 103 & 13 & 2 & 31 & 63 & 19 & 0 & 1 \\
\hline Carrara & 18 & - & 2 & 12 & 2 & 0 & 2 & 0 \\
\hline $\begin{array}{c}\text { Forte dei } \\
\text { Marmi }\end{array}$ & 91 & - & 3 & 27 & 53 & 8 & 0 & 0 \\
\hline Massa & 77 & - & 19 & 30 & 20 & 7 & 1 & 0 \\
\hline Massarosa & 93 & - & 2 & 31 & 30 & 25 & 3 & 2 \\
\hline Montignoso & 79 & - & 9 & 14 & 9 & 26 & 21 & 0 \\
\hline Pietrasanta & 188 & - & 21 & 70 & 49 & 25 & 21 & 2 \\
\hline Serravezza & 33 & - & 5 & 7 & 13 & 8 & 0 & 0 \\
\hline Viareggio & 87 & - & 7 & 24 & 28 & 20 & 8 & 0 \\
\hline TOTAL & 769 & 13 & 70 & 246 & 267 & 138 & 56 & 5 \\
\hline
\end{tabular}

Table 2. CPT database for the macro-area of the Pisa plain.

\begin{tabular}{|c|c|c|c|c|c|c|c|c|}
\hline Municipality & n CPTm & n CPTu & $0<\mathrm{z} \leq 5 \mathrm{~m}$ & $5<\mathrm{z} \leq 8 \mathrm{~m}$ & $8<\mathrm{z} \leq 10 \mathrm{~m}$ & $10<\mathrm{z} \leq 15 \mathrm{~m}$ & $15<\mathrm{z} \leq 20 \mathrm{~m}$ & $>20 \mathrm{~m}$ \\
\hline Bientina & 347 & - & 5 & 85 & 170 & 58 & 15 & 14 \\
\hline Buti & 88 & - & 24 & 17 & 30 & 15 & 0 & 2 \\
\hline Calci & 22 & - & 15 & 5 & 2 & 0 & 0 & 0 \\
\hline Calcinaia & 206 & - & 1 & 21 & 148 & 23 & 13 & 0 \\
\hline Cascina & 510 & - & 7 & 79 & 299 & 69 & 22 & 34 \\
\hline Collesalvetti & 223 & - & 5 & 30 & 84 & 43 & 29 & 32 \\
\hline Crespina & 53 & - & 3 & 7 & 25 & 13 & 4 & 1 \\
\hline Fauglia & 50 & - & 4 & 7 & 24 & 8 & 6 & 1 \\
\hline Lari & 129 & - & 8 & 18 & 68 & 13 & 21 & 1 \\
\hline Livorno & 17 & - & 0 & 0 & 8 & 5 & 1 & 3 \\
\hline Pisa & 488 & - & 14 & 64 & 168 & 133 & 60 & 49 \\
\hline Ponsacco & 338 & - & 7 & 57 & 198 & 47 & 26 & 3 \\
\hline Pontedera & 534 & 3 & 8 & 83 & 301 & 88 & 25 & 32 \\
\hline $\begin{array}{c}\text { San Giuliano } \\
\text { Terme }\end{array}$ & 156 & - & 15 & 19 & 73 & 32 & 3 & 14 \\
\hline Vicopisano & 93 & - & 8 & 21 & 47 & 14 & 3 & 0 \\
\hline Vecchiano & 199 & - & 32 & 48 & 46 & 31 & 22 & 20 \\
\hline TOTAL & 3453 & 3 & 156 & 561 & 1691 & 592 & 250 & 206 \\
\hline
\end{tabular}

Table 3. CPT database for the macro-area of the Lucca plain.

\begin{tabular}{ccccccccc}
\hline Municipality & $\mathbf{n ~ C P T m}$ & $\mathbf{n ~ C P T u}$ & $\mathbf{0}<\mathbf{z} \leq \mathbf{5} \mathbf{m}$ & $\mathbf{5}<\mathbf{z} \leq \mathbf{8} \mathbf{m}$ & $\mathbf{8}<\mathbf{z} \leq \mathbf{1 0} \mathbf{m}$ & $\mathbf{1 0}<\mathbf{z} \leq \mathbf{1 5} \mathbf{m}$ & $\mathbf{1 5}<\mathbf{z} \leq \mathbf{2 0} \mathbf{m}$ & $\mathbf{> 2 0} \mathbf{m}$ \\
\hline Altopascio & 53 & - & 9 & 26 & 9 & 8 & 1 & 0 \\
Capannori & 100 & - & 22 & 34 & 28 & 9 & 7 & 0 \\
Lucca & 80 & - & 25 & 40 & 14 & 1 & 0 & 0 \\
Porcari & 45 & - & 2 & 11 & 17 & 15 & 0 & 0 \\
TOTAL & 278 & 0 & 58 & 111 & 68 & 33 & 8 & 0 \\
\hline
\end{tabular}

Most of the CPTs were performed in the Pisa plain macro-area (77\%, equal to 3456 CPTs), and about half of these tests (49\%) fall within the maximum-depth interval of 8-10 m. Only a small number of CPTs (6\%) reached depths greater than $20 \mathrm{~m}$. The number of CPTs in the Versilia macro-area represents $17 \%$ (equal to $782 \mathrm{CPTs}$ ) of the total number, and $31 \%$ of these tests fall within the maximum-depth interval of 5-8 m. CPTs available in the Lucca plain are 6\% (equal to $278 \mathrm{CPT}$ ) of the entire database. Of these tests, $40 \%$ reached a maximum-depth interval of 5-8 m and only $3 \%$ were in the interval of 15-20 m. Thus, most of the available tests did not exceed the depth of $20 \mathrm{~m}$. As can be easily observed in Tables 1-3, almost the entire database is based on cone penetration tests with a mechanical tip (CPTm).

\section{Main Geological Features and Historical Liquefaction of the Study Area}

From a geological point of view, the study area may be divided into two main sectors-the coastal area of the Pisa plain and Versilia and the innermost zone corresponding to the Lucca plain.

The Lucca plain consists of Quaternary alluvial deposits of the Serchio River. These deposits consist mainly of coarse materials (sands and gravels) at the base, while sands with fines (clay and silts) 
are found at the top. The alluvial deposits overlay a Pliocene, lacustrine clayey horizon [45]. The risk of liquefaction obviously concerns mainly the shallower layers of silt and sand.

On the other hand, the coastal area of the Pisa plain and Versilia consists of very thick Quaternary (mainly Holocene) alluvial deposits of the Arno, Serchio, and other minor rivers. These deposits are granular at the base and cohesive at the top. Alluvial deposits overlay the coastal marine horizons (marine clays). In the area closest to the coastal line, there are also deposits of aeolian sands of limited thickness and extension [45]. From a geological point of view, only Aeolian sands are different with respect to the considered deposits of the Emilia-Romagna region.

Figure 2 shows those areas that are potentially prone to liquefaction. Liquefaction susceptibility is based on geological criteria. The figure distinguishes those areas that in the last 2000 years have been shocked by earthquakes of Intensity VII and VIII of the Mercalli-Cancani-Sieberg (MCS) intensity scale. The dots locate those sites with evidence of liquefaction as reported by Galli and Meloni [47]. The earthquakes that probably caused liquefaction-related phenomena in Tuscany amount essentially to five and occurred in the period between 1542 and 1919 [47]. It is also worth mentioning that, after the Second World War, the study area experienced a remarkable urbanization. Therefore, the major concern is related to recently urbanized areas.

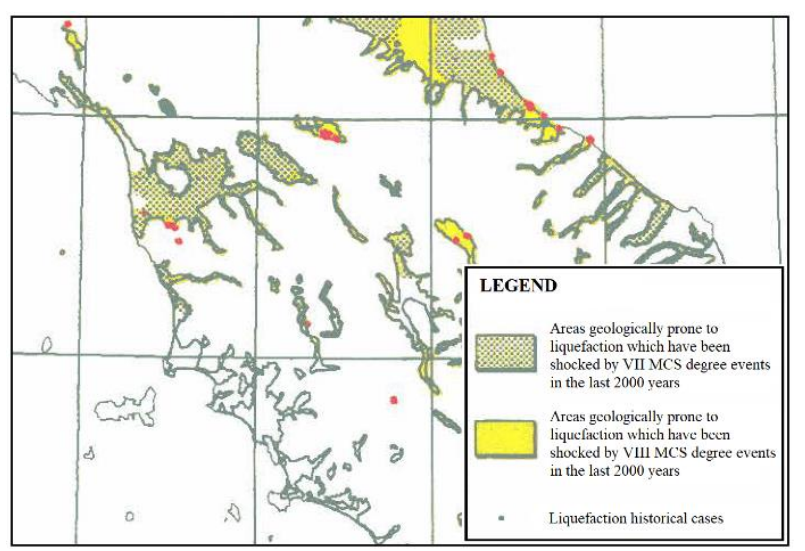

Figure 2. Areas geologically prone to liquefaction in the study area (adapted from Galli and Meloni [47]).

\section{CPT-Based Assessment of Liquefaction Hazard}

In this study, the assessment of the Tuscany region's liquefaction hazard was carried out by using CPT-based LEPs to calculate the factor of safety against liquefaction $\left(\mathrm{FS}_{\mathrm{L}}\right)$ within an LPI framework. The factor of safety was inferred by using the ratio between the cyclic resistance ratio (CRR) and the cyclic stress ratio (CSR) and applying the overburden correction factor $\left(K_{\sigma}\right)$ and the magnitude scaling factor (MSF). The CSR, which represents the seismic demand, is computed according to Equation (1) [1]:

$$
\operatorname{CSR}=0.65 \frac{\sigma_{v}}{\sigma_{v}^{\prime}} \frac{a_{s}}{g} r_{d}
$$

where $\sigma_{v}$ and $\sigma_{v}^{\prime}$ are the total and effective geostatic stress, respectively; $a_{s}$ is the free-field peak ground acceleration at the ground surface of the site of interest; $g$ is the gravity; and $r_{d}$ is a stress reduction factor accounting for the distribution along depth of the shear stress amplitude (soil flexibility). On the whole, both $a_{s}$ and $r_{d}$ should be inferred from site-specific true nonlinear seismic response analysis, accounting for soil strength [48-50]. This is difficult in the case of liquefiable deposits and out of the scope of the present paper. Therefore, in this work, $a_{s}$ was evaluated at each site following the Italian Building Code [46]. The Italian Building Code provides site-dependent parameters at the nodes of a squared grid of $0.05^{\circ}$ size, which covers the entire Italian territory, to define the seismic hazard for each prescribed exceedance probability within a reference period, and thus for each return period. These parameters are as follows: $a_{g}, F_{0}$, and $T_{C}{ }^{*}$ and represent the maximum free-field acceleration 
for a rigid reference site with horizontal topographical surface, the maximum spectral amplification factor, and the period above which the spectral velocity is constant, respectively. The $a_{s}$ value for a given return period is then obtained as the product of $a_{g}$ and the amplification factors $S_{S}$ and $S_{T}$, accounting for the stratigraphy and the topography of the considered site. In particular, the $S_{S}$ amplification factor depends on the ground type, thus on the average shear wave velocity of the first $30 \mathrm{~m}$. In other words, the peak ground acceleration was evaluated on the basis of a probabilistic approach including all scenarios. Moreover, for the present study, three different LEPs were used, as more clearly specified later on. The Boulanger and Idriss [24] and the Juang et al. [19] approaches were applied exactly according to their original formulation. For these methods, the stress reduction factor $r_{d}$ was computed according to Equations (2) to (4) [21], in which $M_{W}$ is the earthquake moment magnitude. The Robertson and Wride [16] method does not clearly define the $K_{\sigma}, M S F$, and $r_{d}$ factors. Indeed, Robertson and Wride [16] suggest, according to Youd et al. [17], to use the $r_{d}$ factor defined by Liao and Whitman [51] and the MSF according to the range suggested by Youd et al. [17]. No indication is given as for the $K_{\sigma}$ factor. Therefore, for this method, we decided to use the same factors as for the Boulanger and Idriss [24] LEP. Of course, such an assumption could be questionable.

$$
\begin{gathered}
r_{d}=\exp \left[\alpha(z)+\beta(z) M_{W}\right] \\
\alpha(z)=-1.012-1.126 \sin \left(\frac{z}{11.73}+5.133\right) \\
\beta(z)=0.106+0.118 \sin \left(\frac{z}{11.28}+5.142\right)
\end{gathered}
$$

The LPI is used as an index of the potential damage at the soil surface level and was computed according to the original formulation proposed by Iwasaki et al. [32] (Equation (5)):

$$
L P I=\int_{0}^{20 m} F_{1} \cdot W(z) d z
$$

where $F_{1}=1-F S_{L}$ for $F S_{L} \leq 1$ and $F_{1}=0$ for $F S_{L}>1 ; W(z)$ is a depth weighting function given by $W(z)$ $=10-0.5 z$; and $z$ is the depth in meters below the ground surface. The LPI can range thus from 0 to a maximum of 100 (i.e., where $F S_{L}$ is zero over the entire $20 \mathrm{~m}$ depth). The level of liquefaction severity can be defined according to the categories suggested by Sonmez [34] or by Iwasaki et al. [32]. In this work, the categories defined in [32] are considered, which assumes for LPI $=0$ that a site is not likely to liquefy and for $0<\mathrm{LPI}<5,5<\mathrm{LPI}<15$, and LPI $>15$ there is a low, high, and very high liquefaction severity, respectively.

\subsection{Definition of the Seismic Demand}

For the definition of the seismic demand, a reference period $\left(V_{R}\right)$ of 50 years was considered, and assuming an exceedance probability $\left(p_{L}\right)$ of $10 \%$ in the reference period, a return period $\left(T_{R}\right)$ of 475 years is obtained using Equation (6) [46]:

$$
T_{R}=-\frac{V_{R}}{\ln \left(1-p_{L}\right)}
$$

The amplification factor $S_{T}$ was assumed equal to 1 , thus considering the topographic area as flat. The factor $S_{S}$ was inferred from the Italian Building Code [46], assuming a ground type $C$, which means a stratigraphic profile characterized by an average shear wave velocity of the first $30 \mathrm{~m}$ between 180 and $360 \mathrm{~m} / \mathrm{s}$. Table 4 shows the values of the free-field peak ground acceleration $\left(a_{s}\right)$ at each municipality considered in this study. The moment magnitude $M_{W}$ (necessary for determining the magnitude scaling factor (MSF)) was first determined by the disaggregation of the seismic hazard for a return period of 475 years [52]. For all the municipalities in the study area, the modal values of $M_{W}$ (from disaggregation) are between 4.5 and 5.0 (Figure 3). On the other hand, the average values of 
$M_{W}$ (Figure 4) for some municipalities are between 4.5 and 5.0, while for others they were between 5.0 and 5.5. For simplicity, it was decided to use a unique value, $M_{W}=5.5$ (corresponding to the upper limit), for all the municipalities of the study area. From a theoretical point of view, the assumption of a unique value of magnitude means considering a single-scenario earthquake. From a practical point of view, such an assumption is responsible, in some municipalities, for a negligible underestimation of the safety factor (less than $8 \%$ ). It is worth mentioning that the moment magnitude affects the MSF. Indeed, the earthquake duration (i.e., the number of cycles of equivalent amplitude) increases with the magnitude, which in turn influences the CRR (i.e., the factor of safety against liquefaction). The factor of safety increases as magnitude $\left(M_{W}\right)$ decreases.

Table 4. Free-field peak ground acceleration $\left(a_{s}\right)$ at each municipality, according to NTC (2018) [46].

\begin{tabular}{|c|c|c|c|}
\hline \multicolumn{2}{|c|}{ Florence } & \multicolumn{2}{|c|}{ Massa Carrara } \\
\hline Municipality & $\mathrm{a}_{\mathrm{S}}(\mathrm{g})$ & Municipality & $a_{s}(g)$ \\
\hline \multirow[t]{3}{*}{ Vicchio } & 0.320 & Carrara & 0.206 \\
\hline & & Montignoso & 0.212 \\
\hline & & Massa & 0.200 \\
\hline \multicolumn{2}{|c|}{ Livorno } & \multicolumn{2}{|l|}{ Pisa } \\
\hline Municipality & $a_{s}(g)$ & Municipality & $a_{s}(g)$ \\
\hline Livorno & 0.182 & Bientina & 0.175 \\
\hline Collesalvetti & 0.208 & Buti & 0.180 \\
\hline \multicolumn{2}{|c|}{ Lucca } & Calci & 0.179 \\
\hline Municipality & $a_{s}(g)$ & Calcinaia & 0.180 \\
\hline Altopascio & 0.191 & Cascina & 0.180 \\
\hline Camaiore & 0.188 & Crespina & 0.210 \\
\hline Capannori & 0.200 & Fauglia & 0.209 \\
\hline Forte dei Marmi & 0.192 & Lari & 0.210 \\
\hline Lucca & 0.196 & Pisa & 0.177 \\
\hline Massarosa & 0.189 & Ponsacco & 0.203 \\
\hline Pietrasanta & 0.196 & Pontedera & 0.190 \\
\hline Porcari & 0.195 & San Giuliano Terme & 0.182 \\
\hline Viareggio & 0.182 & Vicopisano & 0.178 \\
\hline Serravezza & 0.210 & Vecchiano & 0.181 \\
\hline
\end{tabular}

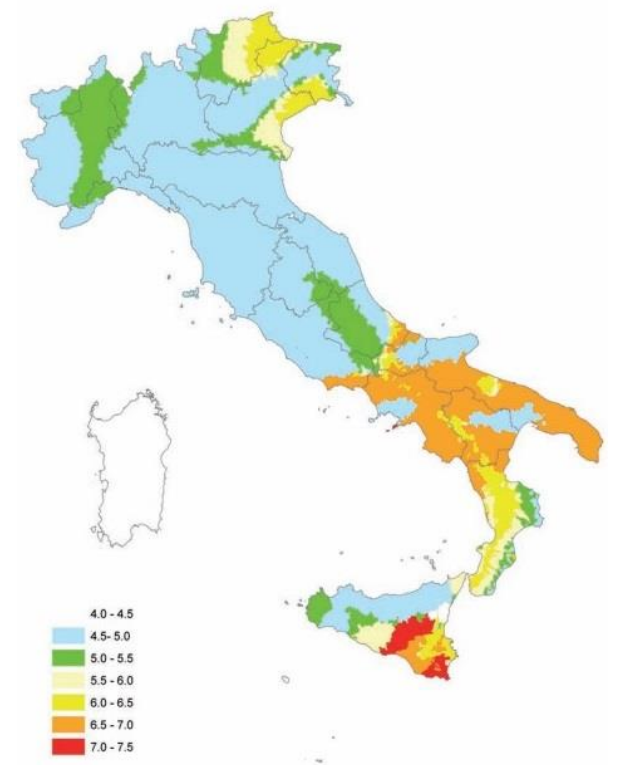

Figure 3. Modal values of $M_{W}$ from disaggregation [52]. 


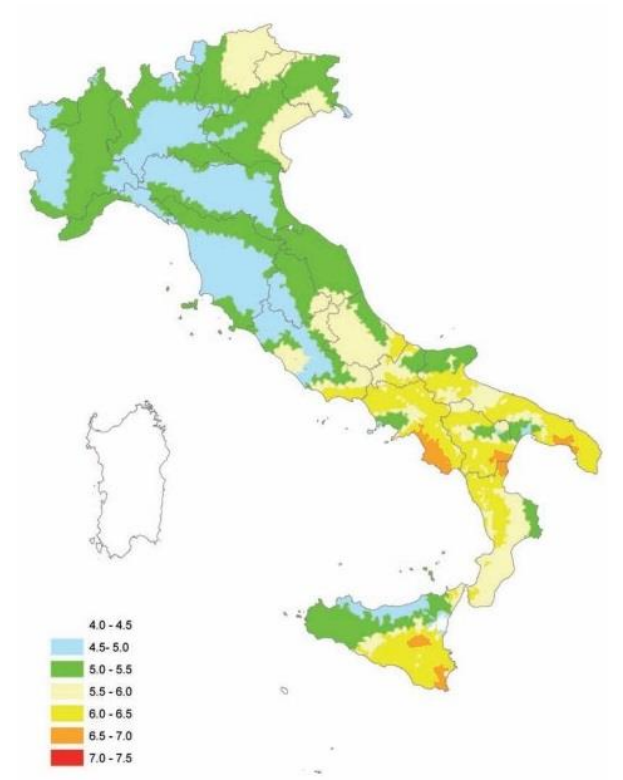

Figure 4. Average values of $M_{W}$ from disaggregation [52].

\subsection{Considered Liquefaction Evaluation Procedures (LEPS)}

This section summarizes the adopted LEPs according to their original definition in order to avoid the mix-up of different approaches. CRR was determined according to the Robertson and Wride [16], Boulanger and Idriss [24], and Juang et al. [19] approaches. The approach proposed by Robertson and Wride [16] computes CRR by using Equations (7) and (8):

$$
\begin{gathered}
C R R=0.833 \cdot \frac{q_{c 1 N, c s}}{1000}+0.05 \text { if } q_{c 1 N, c s}<50 \\
C R R=93\left[\frac{q_{c 1 N, c s}}{1000}\right]^{3}+0.08 \text { if } 50<q_{c 1 N, c s}<160
\end{gathered}
$$

where $q_{c 1 N, c s}$ is the normalized tip resistance corrected to account for the overburden stress and the fine content (FC) and is computed using Equations (9) and (10):

$$
\begin{gathered}
q_{c 1 N}=\frac{q_{c}}{p_{a t m}} \cdot\left(\frac{p_{a t m}}{\sigma_{v}^{\prime}}\right)^{n} \\
q_{c 1 N, c s}=K_{C} \cdot q_{c 1 N}
\end{gathered}
$$

where $p_{a t m}$ is the atmospheric pressure, $q_{c}$ is the measured tip resistance; the $n$ exponent is assumed equal to 1.0 for clayey soil, 0.5 for sandy soil, and 0.75 for silt mixtures; and $K_{C}$ is a correction factor that is computed through Equations (11) and (12):

$$
\begin{gathered}
K_{C}=1.0 \quad \text { if } I_{C} \leq 1.64 \\
K_{C}=-0.403 \cdot I_{C}^{4}+5.581 \cdot I_{C}^{3}-21.63 \cdot I_{C}^{2}+33.75 \cdot I_{C}-17.88 \text { if } I_{C}>1.64
\end{gathered}
$$

where $I_{C}$ is the soil classification index as defined by Robertson and Wride [16] (Equations (13)-(15)):

$$
\begin{gathered}
I_{C}=\left[\left(3.47-\log _{10} Q\right)^{2}+\left(1.22+\log _{10} F\right)^{2}\right]^{0.5} \\
Q=\frac{q_{c}-\sigma_{v}}{p_{a t m}}\left(\frac{p_{a t m}}{\sigma_{v}^{\prime}}\right)^{n}
\end{gathered}
$$




$$
F=\frac{f_{s}}{q_{c}-\sigma_{v}} 100
$$

where $f_{s}$ is the measured sleeve friction.

In the procedure developed by Boulanger and Idriss [24], CRR is computed by using Equation (16):

$$
C R R=\exp \left[\left(\frac{q_{c 1 N, c s}}{113}\right)+\left(\frac{q_{c 1 N, c s}}{1000}\right)^{2}-\left(\frac{q_{c 1 N, c s}}{140}\right)^{3}+\left(\frac{q_{c 1 N, c s}}{137}\right)^{4}-C_{0}\right]
$$

where $C_{0}(=2.6 \pm 0.2)$ is a fitting parameter and $q_{c 1 N, c s}$ is defined by Equation (17), which requires an iterative procedure by using Equations (18) to (22):

$$
\begin{gathered}
q_{c 1 N, c s}=q_{c 1 N}+\Delta q_{c 1 N} \\
q_{c 1 N}=C_{N} \cdot \frac{q_{c}}{p_{a t m}} \\
C_{N}=\left(\frac{p_{a t m}}{\sigma_{v}^{\prime}}\right)^{m} \leq 1.7 \\
m=1.338-0.249 \cdot q_{c 1 N, c s}^{0.264} \\
\Delta q_{c 1 N}=\left(11.9+\frac{q_{c 1 N}}{14.6}\right) \cdot \exp \left[1.63-\frac{9.7}{F C+2}-\left(\frac{15.7}{F C+2}\right)^{2}\right] \\
F C=80 \cdot\left(I_{C}+C_{F C}\right)-137 \quad 0 \leq \mathrm{FC} \leq 100 \%
\end{gathered}
$$

where $C_{F C}$ is a fitting parameter (see Boulanger and Idriss [24] for the suggested value) and $I_{C}$ can be computed using Equation (13) or according to Robertson [38].

In the case of the Boulanger and Idriss [24] and Robertson and Wride [16] approaches, the overburden correction factor $\left(K_{\sigma}\right)$ is computed by using Equations (23) and (24), whereas the MSF is computed by using Equations (25) and (26):

$$
\begin{gathered}
K_{\sigma}=1-C_{\sigma} \ln \left(\frac{\sigma^{\prime}{ }_{v}}{p_{a t m}}\right) \leq 1.1 \\
C_{\sigma}=\frac{1}{37.3-8.27 \cdot\left(q_{c 1 N, c s}\right)^{0.264}} \leq 0.3 \\
M S F=1+\left(M S F_{\max }-1\right)\left[8.64 \exp \left(-\frac{M_{W}}{4}\right)-1.325\right] \\
M S F_{\max }=1.09+\left(\frac{q_{c 1 N, c s}}{180}\right)^{3} \leq 2.2
\end{gathered}
$$

In the approach proposed by Juang et al. [19], CRR is computed by using Equation (27) in the case of a deterministic liquefaction evaluation:

$$
C R R=\exp \left[-2.9439+0.000309 \cdot\left(q_{c 1 N, m}\right)^{1.8}\right]
$$

where $q_{c 1 N, m}$ (Equation (28)) is the stress-normalized tip resistance $q_{c 1 N}$ (Equation (18)) adjusted for the fine effect. In the Juang et al. [19] LEP, $q_{c 1 N}$ is computed via an iterative procedure involving Equations (18) to (20). Please note that, in Equation (20), the term $q_{c 1 N, c s}$ is replaced by the term $q_{c 1 N}$ :

$$
q_{c 1 N, m}=K \cdot q_{c 1 N}
$$


In Equation (28), the adjustment factor, $K$, is part of the regression model shown in Juang et al. [19] and is obtained from Equations (29) to (31):

$$
\begin{gathered}
K=1.0 \text { for } I_{C}<1.64 \\
K=1+80.06 \cdot\left(I_{C}-1.64\right) \cdot\left(q_{c 1 N}\right)^{-1.2194} \quad \text { for } 1.64 \leq I_{C} \leq 2.38 \\
K=1+59.24 \cdot\left(q_{c 1 N}\right)^{-1.2194} \quad \text { for } I_{C}>2.38
\end{gathered}
$$

According to Juang et al. [19], $I_{C}$ is defined in a slightly different way as compared to that defined by Robertson and Wride [16]:

$$
I_{C}=\left[\left(3.47-\log _{10} q_{c 1 N}\right)^{2}+\left(1.22+\log _{10} F\right)^{2}\right]^{0.5}
$$

The factor $K_{\sigma}$ is computed again with Equation (23); nevertheless, $C_{\sigma}$ is defined by Equation (33):

$$
C_{\sigma}=\frac{1}{37.3-8.27 \cdot\left(q_{c 1 N}\right)^{0.264}} \leq 0.3
$$

The magnitude scaling factor (MSF) is then obtained through Equation (34) as suggested by Idriss and Boulanger [22]:

$$
M S F=-0.058+6.9 \cdot \exp \left(\frac{-M_{W}}{4}\right) \leq 1.8
$$

Finally, for all the above described LEPs, the factor of safety against liquefaction $\left(\mathrm{FS}_{\mathrm{L}}\right)$ is computed with Equation (35):

$$
F S_{L}=M S F \cdot K_{\sigma} \cdot \frac{C R R}{C S R}
$$

When using CPTm results in conjunction with the above summarized LEPs, some corrections to measured $f_{s}$ and estimated $I_{C}$ become mandatory, according to the suggestions provided in the works of Meisina et al. [41,42] and briefly described in Section 4.3. These corrections are independent from each other.

\subsection{CPTm Correction Procedure}

The correction procedure for using CPTm results together with available LEPs consists of two empirical correlations [41,42]:

- $\quad$ the first correlation is between $f_{s}$ measured with CPTm and that obtained from CPTu;

- the second correlation is between the correction factor $\left(\Delta I_{C}\right)$ and the cone tip resistance $\left(q_{c}\right)$, which is applied in the case of silt mixtures that are non-correctly identified by the SBTn classification system.

In Meisina et al. [41,42], these two correlations were developed and applied to several pairs (92 pairs in total) of CPTm and CPTu tests to verify their effectiveness in enhancing the identification of liquefiable layers and the evaluation of liquefaction severity by CPTm. The developed approach consists of correcting the sleeve friction $\left(f_{s}\right)$ measured with CPTm and of modifying the estimated value of the soil classification index $\left(I_{C}\right)$ as obtained by interpreting the CPTm data.

The corrected value of $I_{C}$ is only used for improving the soil classification (SBTn), thus it is not applied to Equations (11), (12), (22), and (29)-(31) in which the uncorrected value is still considered. In fact, the use of the SBTn classification system $[16,38,39]$, which is based on CPTu, for the interpretation of CPTm leads on several occasions to an underestimation of the soil grain size, which in turn means an overestimation of $I_{C}$.

The $I_{C}$ correction is only intended to improve the identification of potentially liquefiable layers, i.e., those layers having an $I_{C}$ less than the $I_{C}$ cut-off value. The latter value $\left(I_{C}\right.$ cut-off) is used to screen out clay-like soils and is commonly taken between 2.4 and 2.6 [24]. It is worthwhile to remember that 
those layers with $I_{C}$ higher than $I_{C} c u t$-off are assumed to be non-liquefiable, thus are not considered in the computation of the LPI.

\subsubsection{Sleeve Friction $\left(\mathrm{f}_{\mathrm{s}}\right)$ Correction}

Meisina et al. [41] compared the sleeve friction from CPTm, $f_{s}(\mathrm{CPTm})$, and that from CPTu, $f_{s}(\mathrm{CPTu})$, as obtained from pairs of adjacent $\mathrm{CPTm}-\mathrm{CPTu}$ tests. These tests were carried out at a site in Pisa (central Italy). At the Pisa site, a total of 12 penetration tests ( $3 \mathrm{CPTm}$ and $9 \mathrm{CPTu}$ ) were carried out using a Pagani TG 73/200 penetrometer (Pagani Geotechnical Equipment, Piacenza, Italy) [53]. The capabilities of these tests in identifying the soil layering were also verified due to the availability of three continuous boreholes. The soil stratigraphy at the test site in Pisa is very similar to that existing beneath the Leaning Tower of Pisa $[49,50,54,55]$ and consists of an upper thin layer of silty clay and a thick layer of marine soft clay with an interbedded layer of sand (between 7 and $8 \mathrm{~m}$ depth). The piezometric surface is located about $1 \mathrm{~m}$ below the ground level (GWT). The site was also characterized by a very low horizontal variability. Then, the empirical correlation between $f_{s}(\mathrm{CPTm})$ and $f_{s}(\mathrm{CPTu})$ was established after defining a reasonable strategy for coupling the measured values of $f_{s}$ via the two different test types (CPTm and CPTu). Each value of $f_{s}(\mathrm{CPTm})$ was coupled with an $f_{s}(\mathrm{CPTu})$ value obtained averaging the value of $f_{s}$ at the same depth of the $f_{s}(\mathrm{CPTm})$ with the two values immediately above and below this depth. Pairs of $f_{s}(\mathrm{CPTm})$ and $f_{s}(\mathrm{CPTu})$ values were excluded from the comparison when the corresponding tip resistances $\left(q_{c}(\mathrm{CPTm})\right.$ and $\left.q_{c}(\mathrm{CPTu})\right)$ exhibited a difference higher than $0.25 \mathrm{MPa}$. This limit was established to exclude the comparison between different soil types. Figure 5 shows the ratio $f_{s}(\mathrm{CPTu}) / f_{s}(\mathrm{CPTm})$ vs. $f_{s}(\mathrm{CPTu})$ and the obtained interpolation curve.

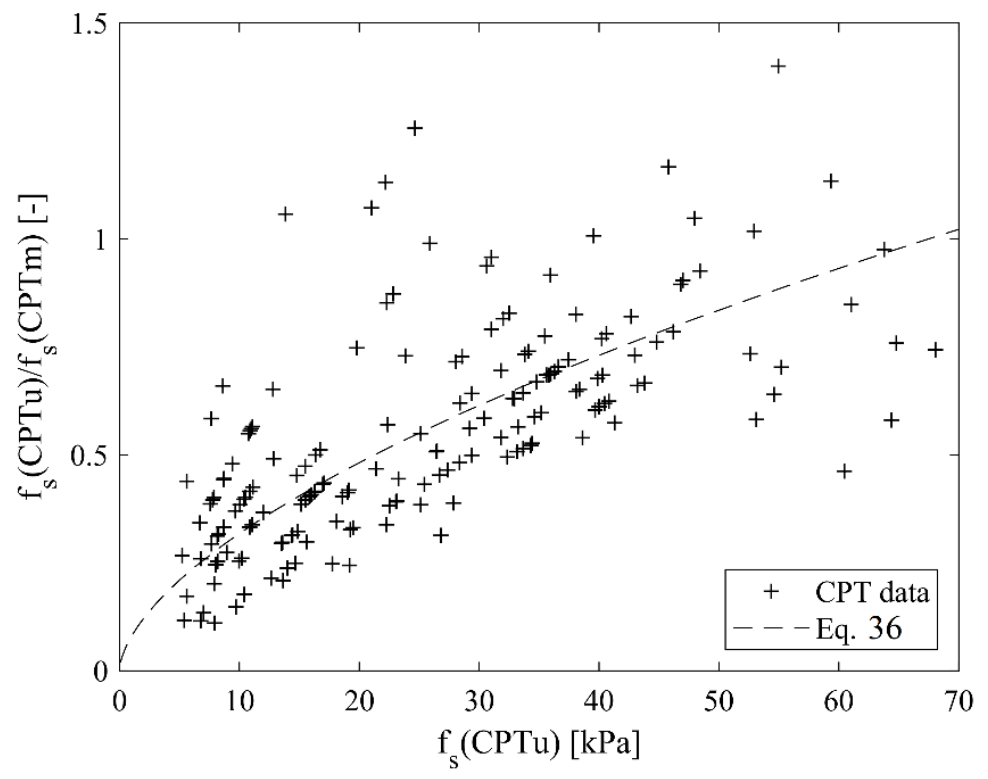

Figure 5. Correlation function between $f_{s}(C P T m)$ and $f_{s}(C P T u)$.

The correlation is applicable only when $f_{s}<65 \mathrm{kPa}$. Thus, $f_{s}(\mathrm{CPTm})$ can be corrected according to Equations (36) and (37) in order to obtain a reasonable estimate of the corresponding value of $f_{s}(\mathrm{CPTu})$.

$$
\begin{gathered}
f_{s}(C P T u)=\left[0.0797 \cdot f_{s}(C P T m)\right]^{2.504} \quad \text { if } f_{s}(C P T m)<65 \mathrm{kPa} \\
f_{s}(C P T u)=f_{s}(C P T m) \quad \text { if } f_{s}(C P T m) \geq 65 \mathrm{kPa}
\end{gathered}
$$

\subsubsection{Soil Classification Index $\mathrm{I}_{\mathrm{C}}$ Correction}

The use of soil behavior type classification charts (i.e., SBT and SBTn charts by Robertson $[38,39]$ and Robertson and Wride [16]), which are based on CPTu, for the interpretation of CPTm generally 
results in an underestimation of the soil grain size. To enable the use of SBTn classification also in the case of CPTm, a correction factor, $\Delta I_{C}$, as a function of the cone tip resistance $\left(q_{c}\right)$ was suggested by Meisina et al. [41]. $\Delta I_{C}$ was defined by establishing a correspondence between the soil classes of the Schmertmann chart [56] and the SBTn classes [16,38,39] (Table 5). For this purpose, a database of 78 CPTm was used. Tests had been carried out in Mirabello, San Carlo, and Sant'Agostino (municipalities located in Emilia-Romagna region and hit by the 2012 Emilia-Romagna seismic sequence). Test results were interpreted using both the Schmertmann [56] and SBTn classification systems. A total of 6141 CPTm measurements were used and the correspondence between these two classification systems, as shown in Table 5, was checked. A perfect match between these systems was achieved in $35 \%$ of the cases, and was mainly observed for SBTn classes 3, 4, and 5. The SBTn system underestimated of one and two classes the Schmertmann [56] classification in $24 \%$ and $16 \%$ of the cases, respectively, while it overestimated of one and two classes the Schmertmann classification in $20 \%$ and $5 \%$ of the cases, respectively. The SBTn overestimate (OE) mainly concerned clayey soils and the SBTn underestimate (UE) was especially observed in sandy soils.

Table 5. Correspondence between Schmertmann [56] and Robertson [38] classification systems (classes 1 and 9 of the Robertson approach were not considered).

\begin{tabular}{|c|c|c|c|c|}
\hline Schmertmann [56] & $I_{C}(\mathrm{PM})$ & SBTn [38] & $I_{C}(\mathrm{SBTn})$ & SBTn Class Description \\
\hline $\begin{array}{l}\text { Organic clay and } \\
\text { mixed soils }\end{array}$ & - & 2 & $I_{C}>3.60$ & Organic soils, peats \\
\hline $\begin{array}{l}\text { Insensitive } \\
\text { non-fissured } \\
\text { inorganic clays }\end{array}$ & 3.275 & 3 & $2.95<I_{C}<3.60$ & Clays: clay to silty clay \\
\hline Sandy and silty clays & 2.775 & 4 & $2.60<I_{C}<2.95$ & $\begin{array}{l}\text { Silt mixtures: silty sand to } \\
\text { sandy silt }\end{array}$ \\
\hline Clayey sands and silts & 2.325 & 5 & $2.05<I_{C}<2.60$ & $\begin{array}{l}\text { Sand mixtures: silty sand to } \\
\text { sandy silt }\end{array}$ \\
\hline Silt-sand mixtures & 2.325 & 5 & $2.05<I_{C}<2.60$ & $\begin{array}{l}\text { Sand mixtures: silty sand to } \\
\text { sandy silt }\end{array}$ \\
\hline Sands & $\begin{array}{c}1.68 \\
-\end{array}$ & $\begin{array}{l}6 \\
7\end{array}$ & $\begin{array}{c}1.31<I_{C}<2.05 \\
I_{C}<1.31\end{array}$ & $\begin{array}{l}\text { Sands: clean sand to } \\
\text { silty sand } \\
\text { Gravely sands to sands }\end{array}$ \\
\hline $\begin{array}{l}\text { Dense or cemented } \\
\text { sands }\end{array}$ & - & 8 & - & Very stiff sand to clayey sand \\
\hline $\begin{array}{l}\text { Very shell sands, } \\
\text { lime rocks }\end{array}$ & - & 8 & - & Very stiff sand to clayey sand \\
\hline
\end{tabular}

Figure 6 clearly shows that the SBTn class 6 has a limited number of cases, while classes 7 and/or 8 are completely absent. On the contrary, the Schmertmann chart [56] exhibits a relevant number of points in the sand and silt/sand areas (Figure 7).

The necessary correction factor, $\Delta I_{C}$, to have a correct match between the two classification systems (Table 5) was thus defined. The proposed correction applies only when the Robertson [38] classification underestimates that of Schmertmann [56] (Equation (38)):

$$
\Delta I_{C}=I_{C}(O V)-I_{C}(P M)
$$

where $I_{C}(\mathrm{OV})$ is the computed $I_{c}$ index (Equation (13)) according to the SBTn system (Robertson, [38]; Robertson and Wride [16]) and $I_{C}(P M)$ is the central value of $I_{C}$ (Table 5) corresponding to the SBTn class that matches the Schmertmann [56] classification (clayey soils were not considered). Figure 8 shows the correction factor $\Delta I_{C}$ as a function of $q_{c}$. 


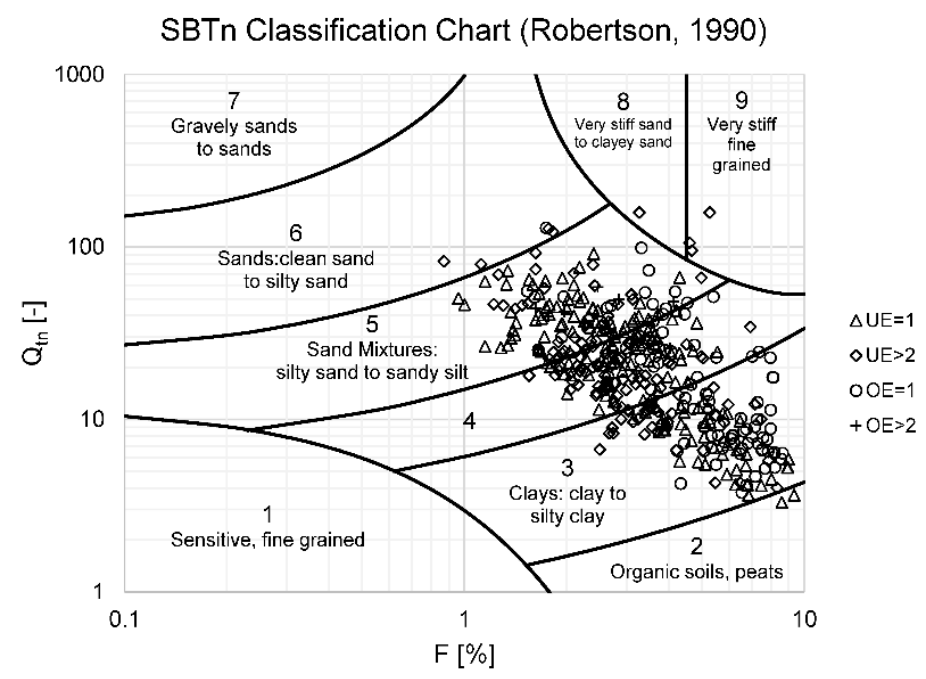

Figure 6. Soil classification from the CPTm results according to Robertson [38].

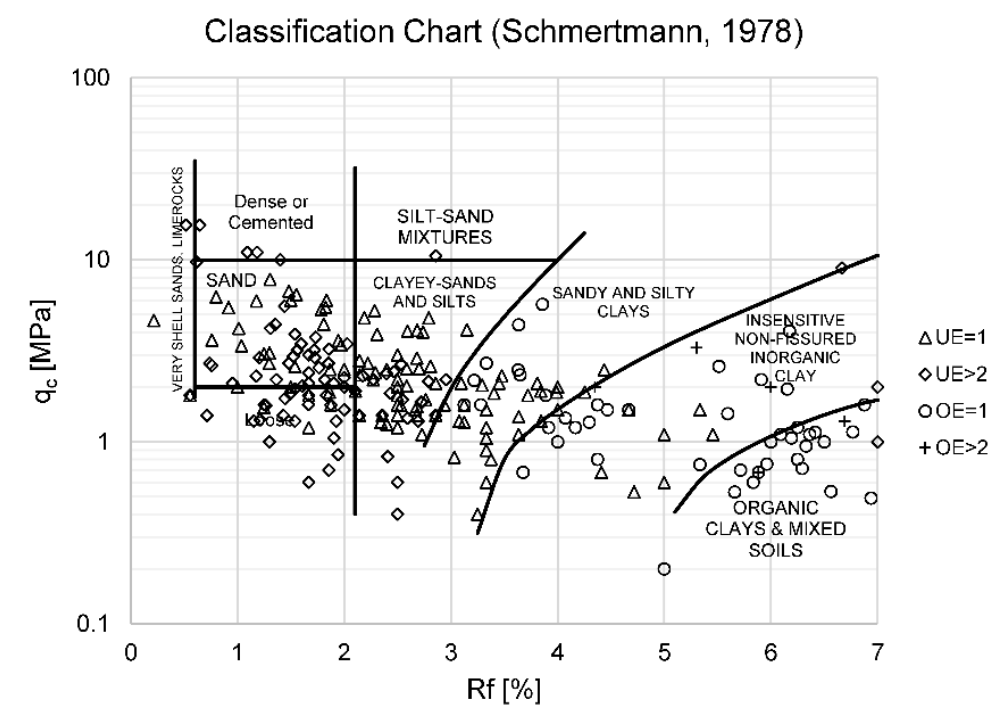

Figure 7. Soil classification from the CPTm results according to Schmertmann [56].

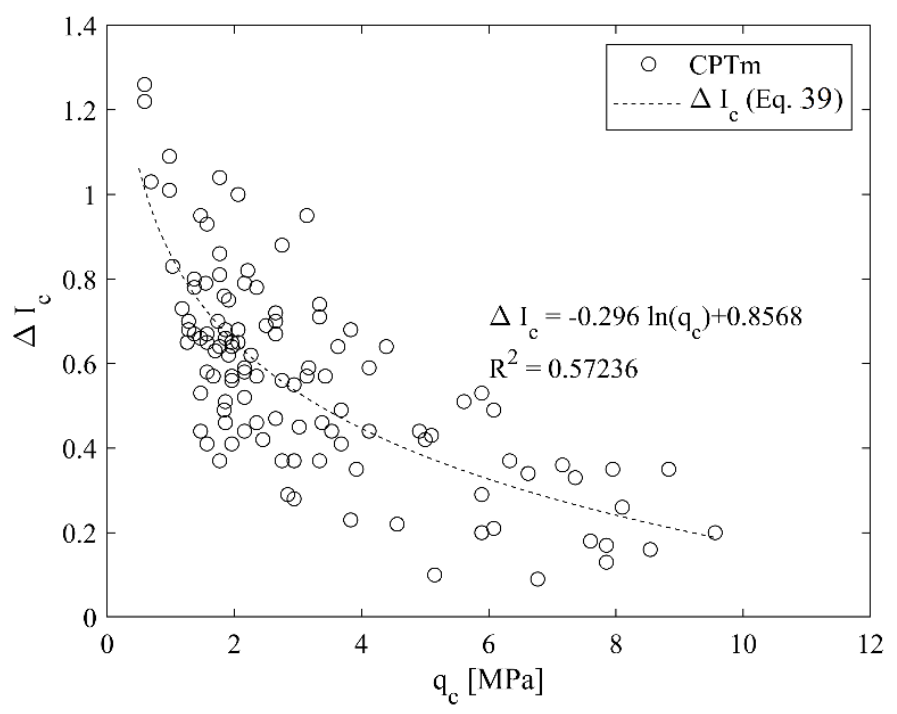

Figure 8. Variation of $\Delta I_{\mathcal{c}}$ vs. $q_{c}$. 
The relationship between the correction factor $\Delta I_{C}$ and the $q_{c}$ inferred by cone testing with a mechanical tip (CPTm) is defined by Equation (39) and should be applied to the $I_{C}$ index (Equation (13)), obtained according to Robertson [38] and Robertson and Wride [16], as shown in Equation (40):

$$
\begin{gathered}
\Delta I_{C}=-0.296 \cdot \ln \left(q_{c}\right)+0.8568 \\
I_{C}(\text { corrected })=I_{C}(\text { Robertson }, 1990)-\Delta I_{C}
\end{gathered}
$$

The correlations presented in Equations (36) and (39) were applied to several pairs of adjacent CPTm and CPTu tests available in the database of the Emilia-Romagna region [41,42]. SBTn profiles inferred by CPTm and CPTu tests were also compared with available borehole profiles. It was confirmed that the use of classification methods that were developed to interpret CPTu mainly causes the loss of sandy to silty liquefiable layers if applied to measured CPTm data [43,57]. Thus, the application of these correlations was shown to be useful to improve the capabilities in identifying the soil layering and liquefiable layers by CPTm. The effectiveness of the correlations was also demonstrated in terms of liquefaction severity indexes [41,42]. In fact, after the application of the correction procedure, the LPI profiles from CPTm were very similar to those obtained from CPTu. Both sites in which liquefaction occurred and sites in which liquefaction did not occur were considered. The predicted liquefaction hazard was consistent with liquefaction phenomena that were observed during the 2012 seismic sequence of Emilia-Romagna.

\section{Liquefaction Hazard Assessment: CPTu vs. CPTm}

The correctness of the proposed approach was verified by considering both some sites in the study area as well other sites in the Emilia-Romagna region (the method was developed by considering 78 pairs of CPTu and CPTm). Table 6 summarizes the relevant information for all the pairs of CPTu and CPTm considered. In Table 6, the first two columns represent the identification code of the CPT tests considered as reported in the Tuscany and Emilia-Romagna databases. Table 6 reports the distances between each CPTm and the respective CPTu test. The pairs of CPTm and CPTu tests in the Tuscany region were available for the following three municipalities: Camaiore (sandy site), Pontedera (clayey site), and Vicchio (sandy site).

\begin{tabular}{|c|c|c|c|c|c|c|c|}
\hline CPTu & CPTm & Distance (m) & GWT (m) & Region & Municipality & $a_{s}(g)$ & Magnitude \\
\hline 28000599_CPT_6688 & 28000599_CPT_6666 & 38.70 & 3.12 & Tuscany & Pontedera & 0.19 & 5.5 \\
\hline 28000599_CPT_6690 & 28000599_CPT_6669 & 29.82 & 2.62 & Tuscany & Pontedera & 0.19 & 5.5 \\
\hline 28000599_CPT_6689 & 28000599_CPT_9995 & 18.77 & 3.43 & Tuscany & Pontedera & 0.19 & 5.5 \\
\hline CPTU4 & 00634 & 99.18 & 1.80 & Tuscany & Camaiore & 0.188 & 5.5 \\
\hline CPTU7 & 00224 & 147.80 & 1.95 & Tuscany & Camaiore & 0.188 & 5.5 \\
\hline CPTe11 & CPT1 & 2.00 & 2.0 & Tuscany & Vicchio & 0.32 & 6.37 \\
\hline CPTe13 & CPT6 & 2.00 & 2.0 & Tuscany & Vicchio & 0.32 & 6.37 \\
\hline CPTe15 & CPT9bis & 10.00 & 2.0 & Tuscany & Vicchio & 0.32 & 6.37 \\
\hline CPTu (203010U502) & CPT (203010C121) & 13.00 & 1.20 & Emilia-Romagna & Sant'Agostino & 0.21 & 5.9 \\
\hline CPTu (185130U508) & CPT (185130C142) & 36.00 & 3.80 & Emilia-Romagna & Sant'Agostino & 0.21 & 5.9 \\
\hline CPTu (185130U512) & CPT (185130C137) & 36.00 & 4.50 & Emilia-Romagna & Sant'Agostino & 0.21 & 5.9 \\
\hline CPTu (185130U514) & CPT (185130C135) & 24.00 & 4.55 & Emilia-Romagna & Sant'Agostino & 0.21 & 5.9 \\
\hline
\end{tabular}

Table 6. Pairs of CPTm and CPTu in the study area (Tuscany region) and in Emilia-Romagna.

Figure 9 compares the outcome, in terms of LPI, of the application of the three LEPs $[16,19,24]$ for the 14 CPTu tests in Table 6. As can be observed, these three LEPs provide very similar results. Indeed, these LEPs were developed based on CPTu tests. Nearly zero values of the LPI were obtained from the CPTs in the municipality of Pontedera, which is characterized by clayey deposits. 


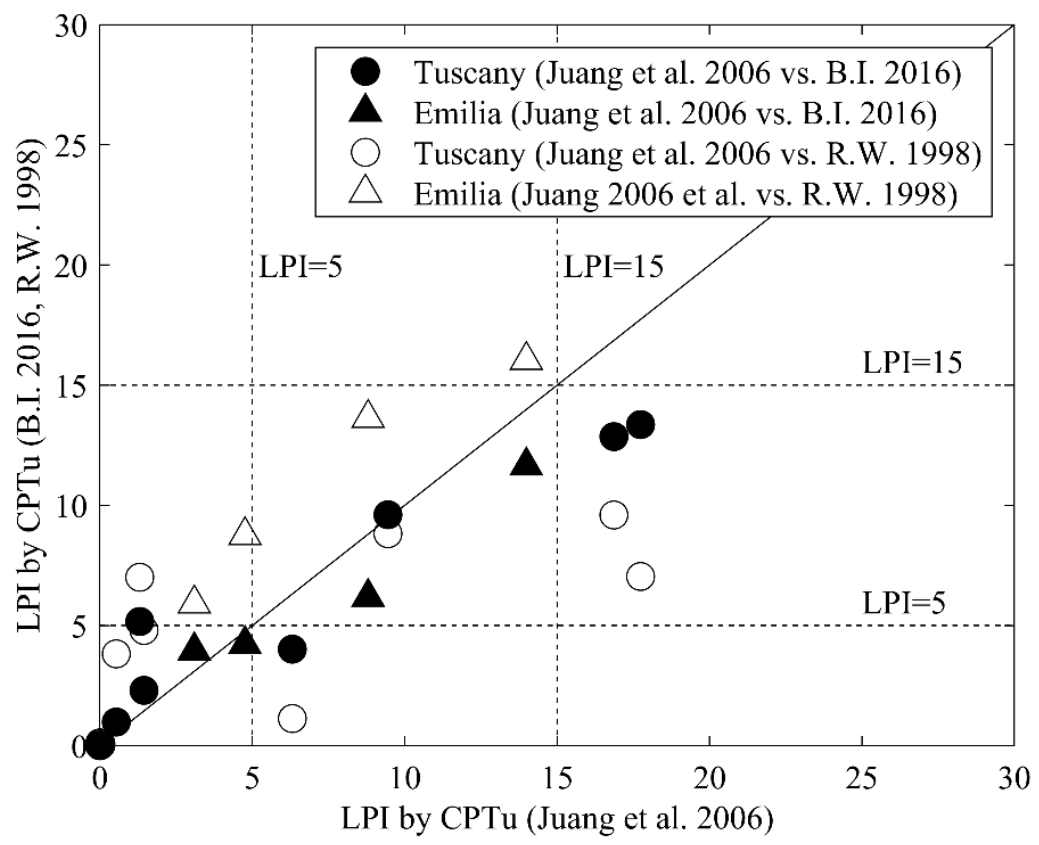

Figure 9. Comparison between the values of the Liquefaction Potential Index (LPI) obtained with CPTu by using all the considered liquefaction evaluation procedures (LEPs). B.I. = Boulanger and Idriss; R.W. $=$ Robertson and Wride.

In contrast, Figures 10 and 11 show the LPI values obtained by using the considered LEPs in the 14 CPTm tests in Table 6 without (w/o) and with applying the correction procedure described in Section 4.3, respectively. Figure 10 clearly shows that the application of these LEPs to uncorrected CPTm data results in an underestimation of the LPI values in all the 14 cases if compared to those in Figure 9, and that the LEPs are no longer in good agreement.

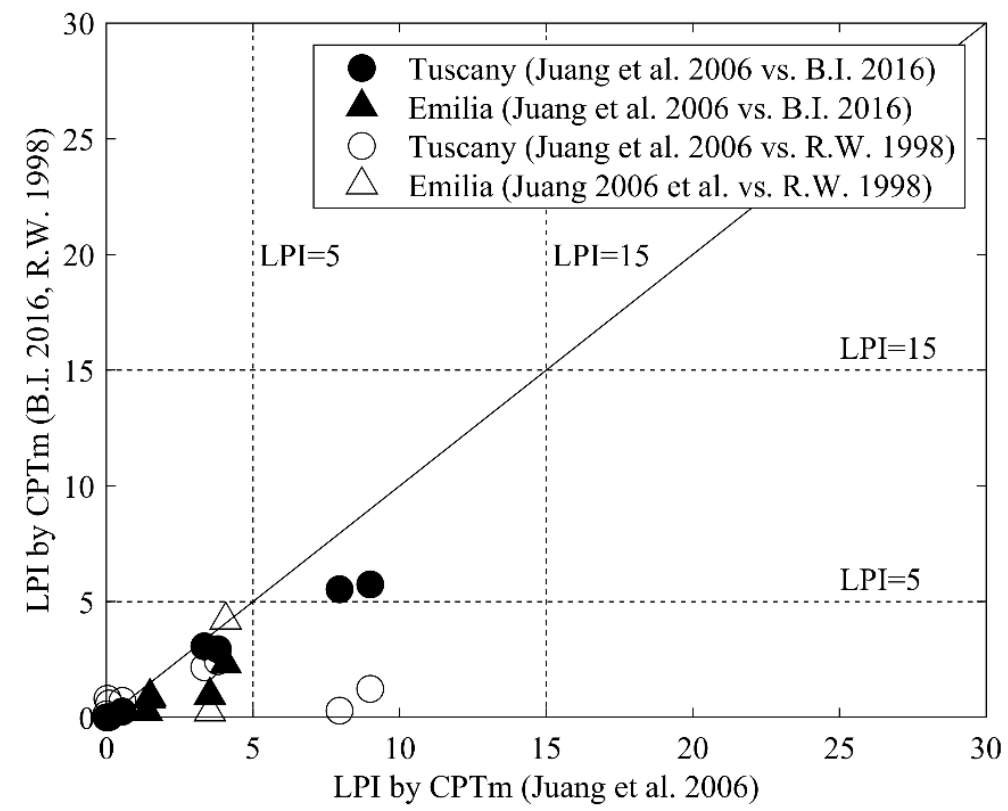

Figure 10. Comparison between the values of the LPI obtained with uncorrected CPTm data by using all the considered LEPs. B.I. = Boulanger and Idriss; R.W. = Robertson and Wride. 


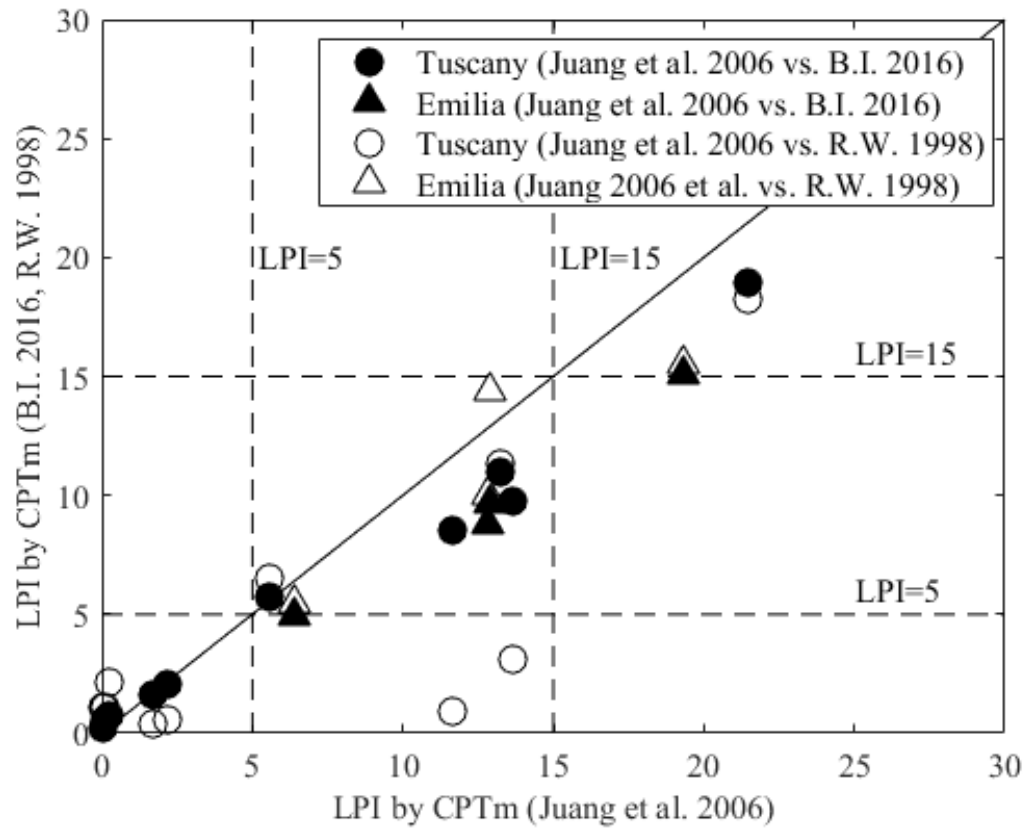

Figure 11. Comparison between the values of the LPI obtained with corrected CPTm data by using all the considered LEPs. B.I. = Boulanger and Idriss; R.W. = Robertson and Wride.

Figure 11 shows that the application of the correction procedure, which involves some corrections to the measured $f_{s}$ and estimated $I_{C}$, permits to obtain LPI values which are closer to or higher than those obtained from CPTu tests (Figure 9). This is clearly shown in Figure 12 in which the LPI by CPTu and the LPI by CPTm (with and w/o corrections) are compared when considering the LEPs developed by Boulanger and Idriss [24] and Juang et al. [19]. In any case, there is no historical evidence of liquefaction phenomena in the study areas (Tuscany) to confirm the correctness of the predictive capacity of the considered LEPs.
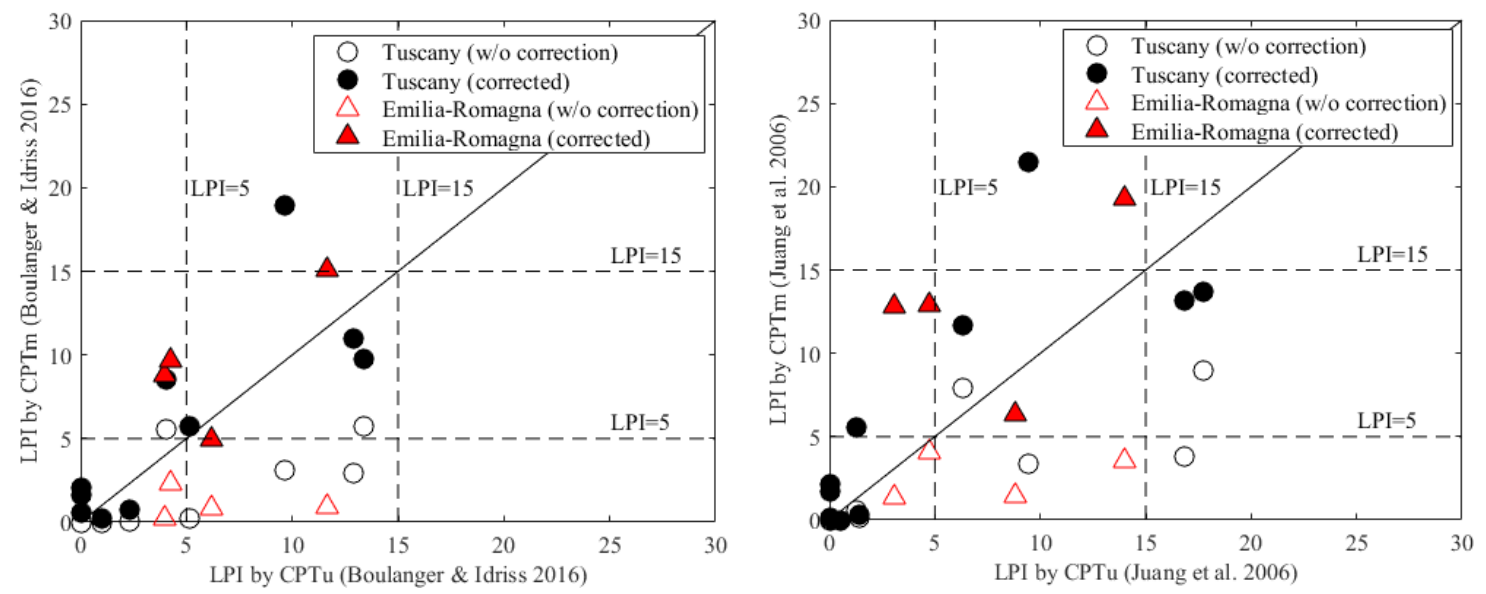

Figure 12. Comparison between the values of the LPI obtained with CPTu and CPTm (with and w/o corrections) by using the LEPs proposed by Boulanger and Idriss [24] (left) and Juang et al. [19] (right).

The CPTm-CPTu pair (CPTu 13-CPTm 6, Table 6) in the Vicchio site is used here to demonstrate the effectiveness of the correction procedure [41,42]. Figure 13 shows measured $q_{c}, f_{s}$, and computed $I_{C}$ (Robertson and Wride [16]) profiles as obtained from CPTu (black continuous line) and CPTm (red dashed line). Corrected $f_{s}$ and $I_{\mathcal{C}}$ values are those blue points that are not located above the red dashed lines (uncorrected CPTm data). In this site, the GWT was located $2.0 \mathrm{~m}$ below the ground 
level. The correction procedure mainly modifies the $f_{s}$ and $I_{C}$ values between $1-2$ and 5-8 $\mathrm{m}$ in depth. Therefore, the corrected values of $f_{s}$ and $I_{C}$ modify the LPI.
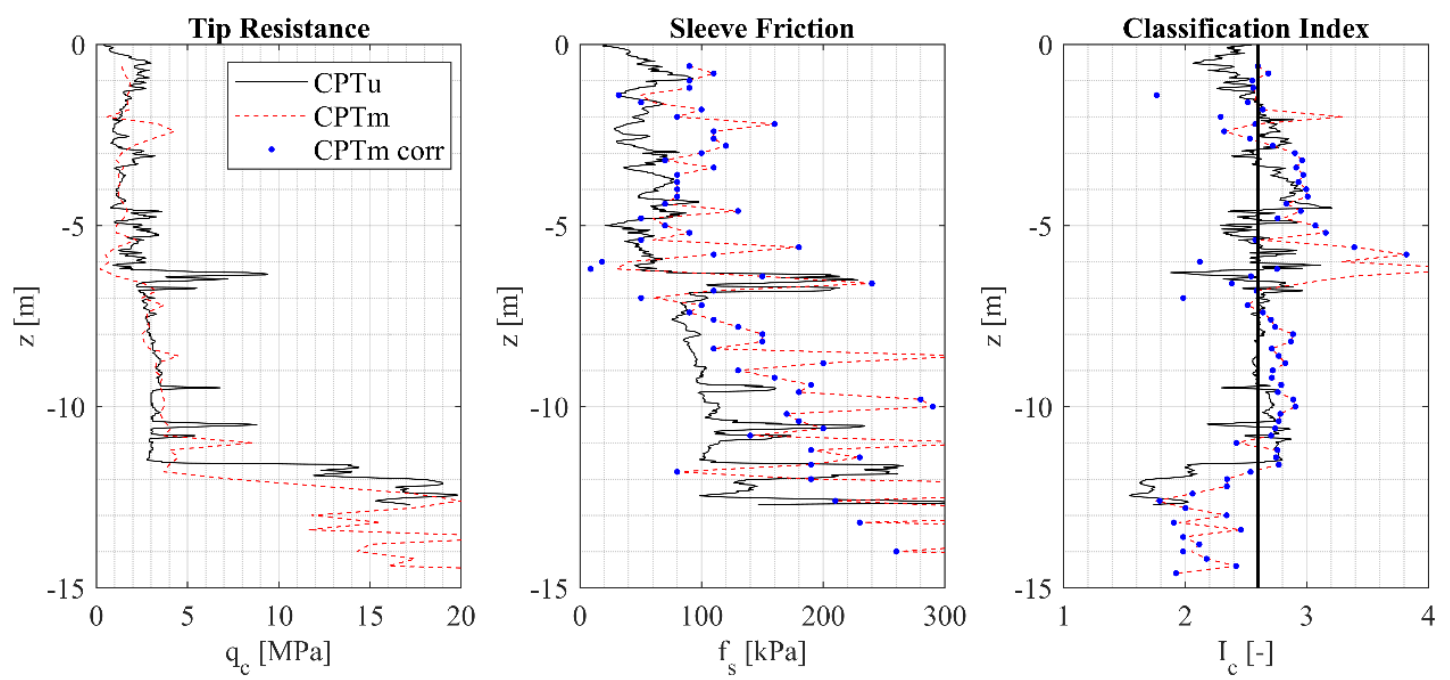

Figure 13. $q_{c}(z), f_{s}(z)$, and $I_{C}(z)$ profiles (CPTu 13, CPTm 6 , and CPTm 6 corrected, Vicchio site).

Figure 14 shows the effect of the corrections by using the Boulanger and Idriss [24], Robertson and Wride [16], and Juang et al. [19] LEPs, respectively, in terms of LPI profiles. Looking at Figure 14, the LPI values obtained from CPTm after corrections are closer to those inferred from CPTu for the test site considered.
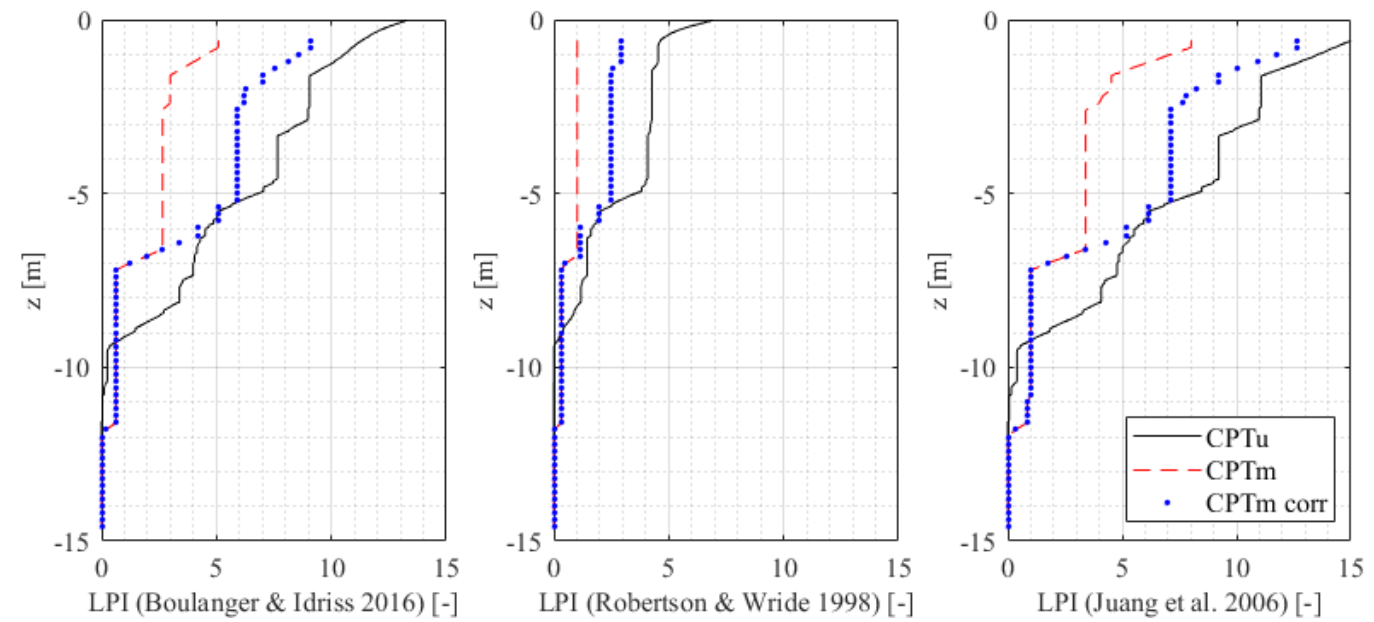

Figure 14. $L P I(z)$ profiles obtained by using the three LEPs considered (CPTu 13, CPTm 6, and CPTm 6 corrected).

\section{Liquefaction Hazard Assessment for the Study Area}

The three considered LEPs and the correction procedure were applied to the whole CPT database to assess the liquefaction hazard of the study areas. Tables 7-9 and Figures 15-17 summarize the results. In Table 7 (Versilia macro-area) and 9 (Pisa plain macro-area), the results refer to those CPTm and CPTu with depths equal to or higher than $15 \mathrm{~m}$. In Table 8 (Lucca plain macro-area), due to the limited number of CPTm and CPTu tests the results refer to those tests with depths equal to or higher than $10 \mathrm{~m}$. As already shown, the methods give different results even without any correction in the case of CPTm. These differences are not due to the proposed correction procedure but are intrinsic differences among different LEPs. More specifically, the Juang et al. [19] and Boulanger and Idriss [24] methods give similar estimates of LPI. 
Table 7. Liquefaction severity classes for the macro-area of Versilia (CPTs with depth $\geq 15 \mathrm{~m}$ ).

\begin{tabular}{ccccccc}
\hline LPI & $\begin{array}{c}\text { Boulanger } \\
\text { and Idriss } \\
\text { [24] }\end{array}$ & $\begin{array}{c}\text { Boulanger } \\
\text { and Idriss [24] } \\
\text { Corrected }\end{array}$ & $\begin{array}{c}\text { Robertson } \\
\text { and Wride } \\
{[16]}\end{array}$ & $\begin{array}{c}\text { Robertson } \\
\text { and Wride [16] } \\
\text { Corrected }\end{array}$ & $\begin{array}{c}\text { Juang et al. } \\
\text { [19] }\end{array}$ & $\begin{array}{c}\text { Juang et al. } \\
\text { [19] Corrected }\end{array}$ \\
\hline LPI = 0 & $21(20.8 \%)$ & $6(5.9 \%)$ & $16(15.8 \%)$ & $2(2.0 \%)$ & $24(23.8 \%)$ & $13(12.9 \%)$ \\
$\mathbf{0}<$ LPI $\leq \mathbf{5}$ & $67(66.3 \%)$ & $49(48.5 \%)$ & $71(70.3 \%)$ & $32(31.7 \%)$ & $59(58.4 \%)$ & $29(28.7 \%)$ \\
$\mathbf{5}<$ LPI $\leq \mathbf{1 5}$ & $13(12.9 \%)$ & $35(34.7 \%)$ & $12(11.9 \%)$ & $46(45.5 \%)$ & $17(16.8 \%)$ & $46(45.5 \%)$ \\
LPI > 15 & $0(0.0 \%)$ & $11(10.9 \%)$ & $2(2.0 \%)$ & $21(20.8 \%)$ & $1(1.0 \%)$ & $13(12.9 \%)$ \\
\hline
\end{tabular}

Table 8. Liquefaction severity classes for the macro-area of the Lucca plain (CPTs with depth $\geq 10 \mathrm{~m}$ ).

\begin{tabular}{ccccccc}
\hline LPI & $\begin{array}{c}\text { Boulanger } \\
\text { and Idriss } \\
\text { [24] }\end{array}$ & $\begin{array}{c}\text { Boulanger } \\
\text { and Idriss [24] } \\
\text { Corrected }\end{array}$ & $\begin{array}{c}\text { Robertson } \\
\text { and Wride } \\
\text { [16] }\end{array}$ & $\begin{array}{c}\text { Robertson } \\
\text { and Wride [16] } \\
\text { Corrected }\end{array}$ & $\begin{array}{c}\text { Juang et al. } \\
\text { [19] }\end{array}$ & $\begin{array}{c}\text { Juang et al. } \\
\text { [19] Corrected }\end{array}$ \\
\hline LPI = 0 & $13(22.0 \%)$ & $3(5.1 \%)$ & $6(10.2 \%)$ & $2(3.4 \%)$ & $14(23.7 \%)$ & $4(6.8 \%)$ \\
$\mathbf{0}<$ LPI $\leq \mathbf{5}$ & $46(78.0 \%)$ & $37(62.7 \%)$ & $53(89.8 \%)$ & $18(30.5 \%)$ & $45(76.3 \%)$ & $40(67.8 \%)$ \\
$\mathbf{5}<$ LPI $\leq \mathbf{1 5}$ & $0(0 \%)$ & $15(25.4 \%)$ & $0(0 \%)$ & $25(42.4 \%)$ & $0(0 \%)$ & $11(18.6 \%)$ \\
LPI > 15 & $0(0 \%)$ & $4(6.8 \%)$ & $0(0 \%)$ & $14(23.7 \%)$ & $0(0 \%)$ & $4(6.8 \%)$ \\
\hline
\end{tabular}

Table 9. Liquefaction severity classes for the macro-area of the Pisa plain (CPTs with depth $\geq 15 \mathrm{~m}$ ).

\begin{tabular}{ccccccc}
\hline LPI & $\begin{array}{c}\text { Boulanger } \\
\text { and Idriss } \\
\text { [24] }\end{array}$ & $\begin{array}{c}\text { Boulanger } \\
\text { and Idriss [24] } \\
\text { Corrected }\end{array}$ & $\begin{array}{c}\text { Robertson } \\
\text { and Wride } \\
{[16]}\end{array}$ & $\begin{array}{c}\text { Robertson } \\
\text { and Wride [16] } \\
\text { Corrected }\end{array}$ & $\begin{array}{c}\text { Juang et al. } \\
\text { [19] }\end{array}$ & $\begin{array}{c}\text { Juang et al. } \\
\text { [19] Corrected }\end{array}$ \\
\hline LPI = 0 & $178(27.5 \%)$ & $9(1.4 \%)$ & $145(22.4 \%)$ & $10(1.5 \%)$ & $160(24.7 \%)$ & $8(1.2 \%)$ \\
$\mathbf{0}<$ LPI $\leq \mathbf{5}$ & $454(70.1 \%)$ & $171(26.4 \%)$ & $484(74.7 \%)$ & $157(24.2 \%)$ & $471(72.7 \%)$ & $204(31.5 \%)$ \\
$\mathbf{5}<$ LPI $\leq \mathbf{1 5}$ & $12(1.9 \%)$ & $275(42.4 \%)$ & $11(1.7 \%)$ & $242(37.3 \%)$ & $12(1.9 \%)$ & $260(40.1 \%)$ \\
LPI $>\mathbf{1 5}$ & $4(0.6 \%)$ & $193(29.8 \%)$ & $8(1.2 \%)$ & $239(36.9 \%)$ & $5(0.8 \%)$ & $176(27.2 \%)$ \\
\hline
\end{tabular}

Boulanger \& Idriss (2016) - Versilia area

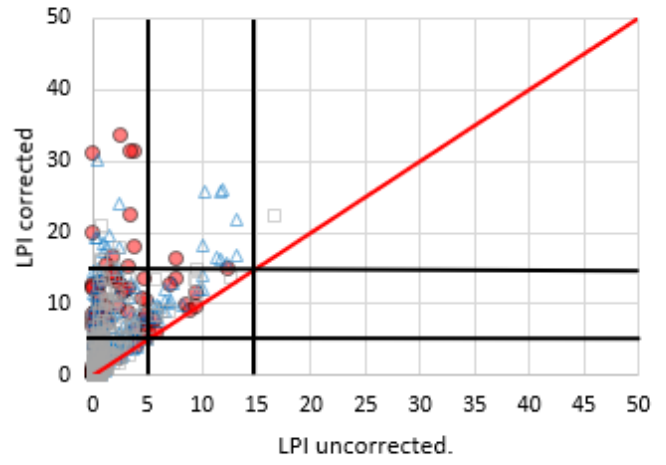

Juang et al. (2006) - Versilia area

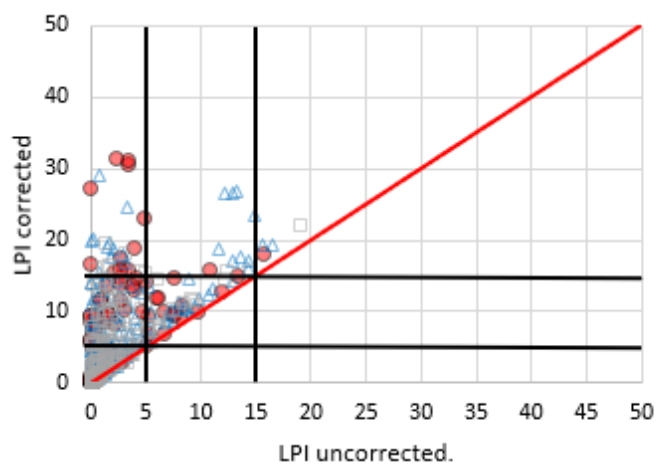

Robertson \& Wride (1998) - Versilia area

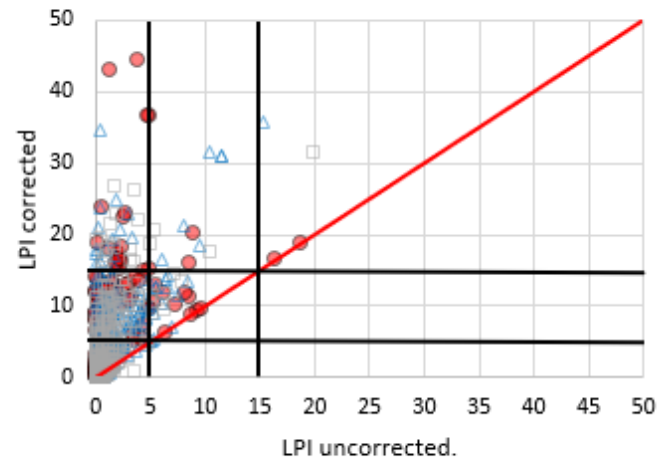

Figure 15. LPI (corrected) vs. LPI (w/o corrections) for the macro-area of Versilia. 
Boulanger \& Idriss (2016) - Lucca plain

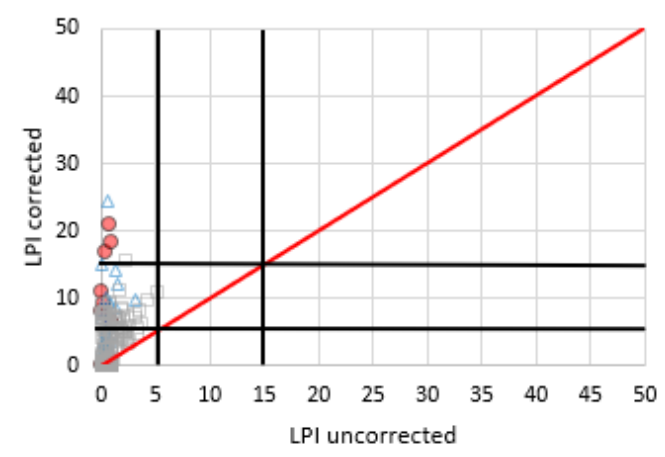

Juang et al. (2006) - Lucca plain

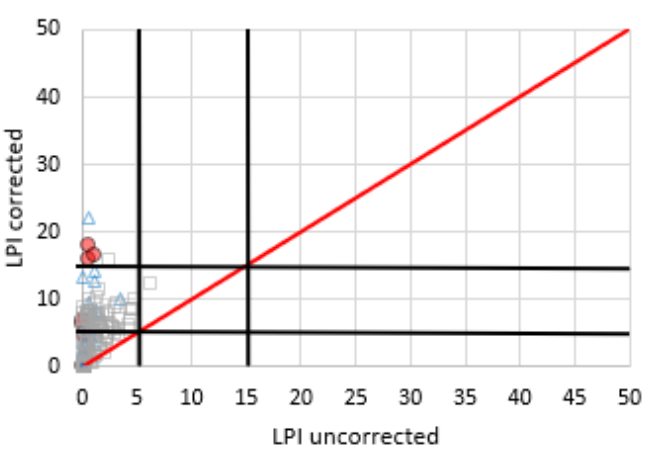

Robertson \& Wride (1998) - Lucca plain

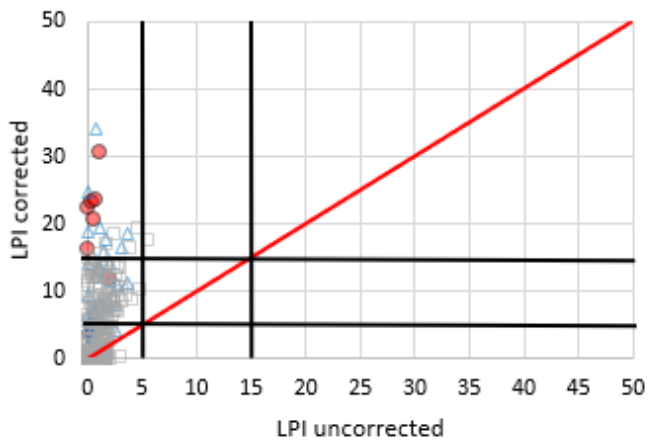

Figure 16. LPI (corrected) vs. LPI (w/o corrections) for the macro-area of the Lucca plain.

Boulanger \& Idriss (2016) - Pisa plain

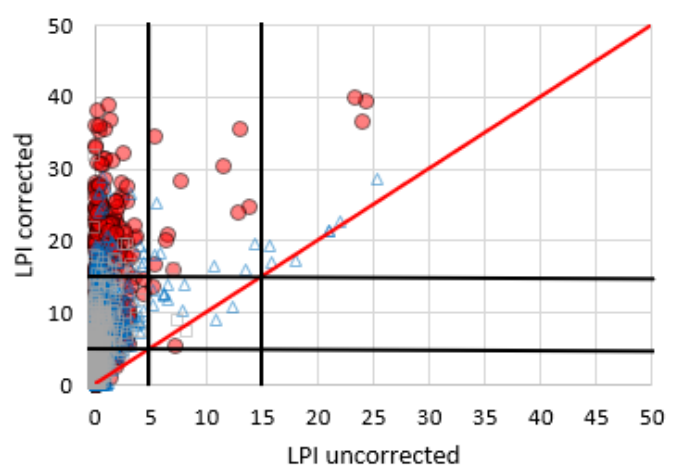

Juang et al. (2006) - Pisa plain

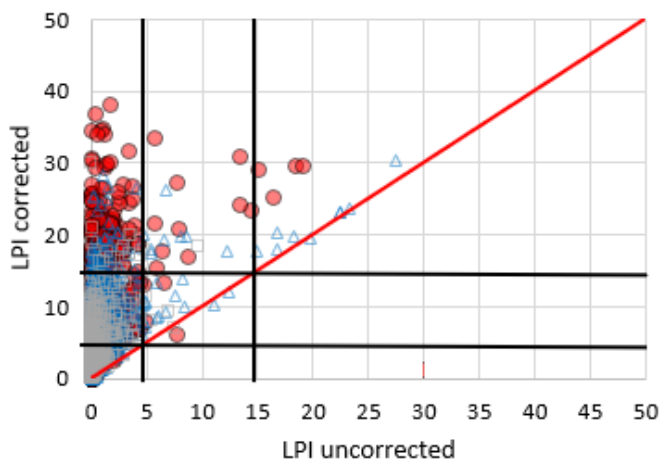

Robertson \& Wride (1998) - Pisa plain

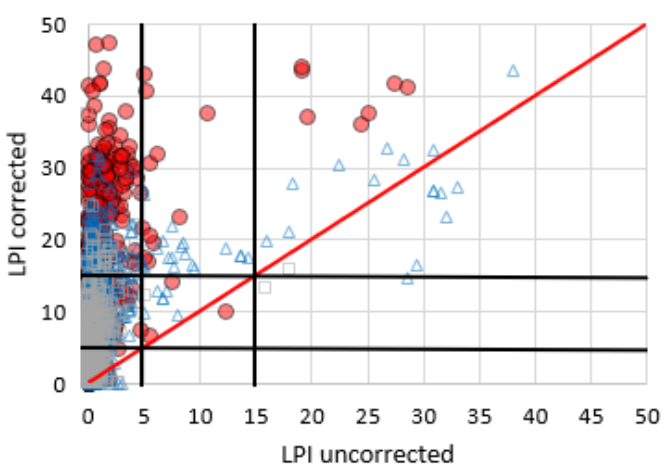

- depth $>15 \mathrm{~m}$

$\triangle 10 \mathrm{~m}<$ depth $<15 \mathrm{~m}$

depth $<10 \mathrm{~m}$

\footnotetext{
- depth $>15 \mathrm{~m}$

$\Delta 10 \mathrm{~m}<$ depth $<15 \mathrm{~m}$

depth $<10 \mathrm{~m}$
}

Figure 17. LPI (corrected) vs. LPI (w/o corrections) for the macro-area of the Pisa plain. 
When applying the proposed approach to the whole database, the Robertson and Wride [16] method gives the higher increase of the LPI, whereas in the case of the Boulanger and Idriss [24] and Juang et al. [19] LEPs, the increase of the LPI is less dramatic.

In more detail, it is possible to observe that:

(1) for the Versilia macro-area (Table 7, Figure 15), where most of the available tests were carried out down to depths of 5-8 $\mathrm{m}(31 \%)$ and $8-10 \mathrm{~m}(24 \%)$, the three LEPs without applying the $f_{S}$ and $I_{\mathcal{C}}$ corrections agree to recognize a zero or low severity for most of the tests. After applying the corrections described in Section 4.3 to the Robertson and Wride [16] method, the high severity and very high severity classes increase from $11.9 \%$ and $2.0 \%$ to about $45.5 \%$ and $20.8 \%$, respectively (considering only those tests with depths equal to or higher than $15 \mathrm{~m}$ ). When the corrections are applied to the Boulanger and Idriss [24] and Juang et al. [19] approaches, the increase in the high and very high severity classes is less dramatic, especially for the very high severity class (LPI > 15);

(2) for the macro-area of the Lucca plain (Table 8, Figure 16), where $40 \%$ and $24 \%$ of the available tests were carried out down to depths of 5-8 $\mathrm{m}$ and 8-10 $\mathrm{m}$, respectively, the three LEPs without applying the $f_{S}$ and $I_{\mathcal{C}}$ corrections agree to classify all the tests in the zero or low severity classes. Very different results are obtained after applying the corrections. In fact, only $30.5 \%$ of the tests remain in the low, $42.4 \%$ fall in the high, and $23.7 \%$ in the very high severity class by using the LEP by Robertson and Wride [16] (considering only those tests with depths equal to or higher than $10 \mathrm{~m}$ ). After applying the corrections to the Boulanger and Idriss [24] and Juang et al. [19] approaches, especially the very high severity class increases in a negligible way;

(3) for the macro-area of the Pisa plain (Table 9, Figure 17), where 49\%, 17\%, and 6\% of the available tests were carried out down to depths of 8-10 m, 10-15 m, and greater than $20 \mathrm{~m}$, respectively, the three LEPs without applying the $f_{S}$ and $I_{\mathcal{C}}$ corrections agree to classify most of the tests in the zero or low liquefaction severity classes. After applying the corrections, the three LEPs exhibit the same trend that was observed for the other two macro-areas, even though with different percentages.

More importantly, regardless of the large numbers of tests that were analyzed, it was not possible to define areas with very high or negligible liquefaction potential. Indeed, the LPI values were casually spread all over the study area and clustering was not possible [45]. Therefore, it is only possible to recommend the most appropriate LEP to be used for the design of new construction projects or the retrofitting of existing ones.

In order to state which of the three LEPs give more realistic predictions, it is necessary to consider the historical seismicity of the study areas as well as historical evidence of liquefaction. In particular, the following facts should be considered:

- the study area could be split into two main classes: urbanized areas that have existed for many centuries and areas that were only urbanized after the Second World War. More specifically, the near-sea plains were uninhabited until the end of the Second World War. Indeed, these areas have only been urbanized since the 1960s. The database was developed mainly to help in evaluating the liquefaction risk in recently urbanized areas;

- $\quad$ on the other hand, there is no historical evidence of relevant liquefaction phenomena in the historically inhabited areas. Therefore, for those areas, a low to moderate liquefaction risk is expected;

- a similar or not very different picture is expected for recently urbanized areas in the case of the same geological features (Holocene, alluvial deposits mainly consisting of sand and silt mixtures);

- $\quad$ it has been shown that the Robertson and Wride [16] approach gives higher values of the LPI. On the other hand, the applied corrections have the only aim of obtaining the same predictions from both CPTm and CPTu. The results obtained with this approach could have been affected by the assumptions we made regarding some factors (i.e., $r_{d}, M S F$ and $K_{\sigma}$ ); 
- therefore, the above considerations suggest that the corrected Boulanger and Idriss [24] and Juang et al. [19] approaches could be the most appropriate for the study area.

Moreover, the execution of additional "deep" CPTu tests in the study area is underway and will help in clarifying some aspects of the proposed approach that remain not well defined, even though this will take a long time for several reasons. The GIS-referenced database and the liquefaction hazard analysis results as obtained with the three uncorrected and corrected LEPs are available at the Tuscany region's website (http://www.regione.toscana.it/speciali/rischio-sismico).

\section{Conclusions}

A GIS-referenced database of CPTm from the coastal area of Tuscany was implemented. Unfortunately, most of the tests did not reach depths as high as $20 \mathrm{~m}$. A recently proposed correction procedure was applied to CPTm data to obtain results that were similar to those inferred from $\mathrm{CPTu}$. Even though the use of CPTu remains highly recommended for liquefaction hazard analyses, this methodology is a very useful tool for those countries where huge CPTm databases are available.

From the comparison between the LPI values obtained from CPTu and CPTm, it was generally found that:

- when the corrections are applied to CPTm, the three considered LEPs predict the same severity class inferred from CPTu;

- $\quad$ among the three LEPs used herein, those proposed by Boulanger and Idriss [24] and Juang et al. [19] lead to very similar results;

- in any case, the Robertson and Wride [16] approach leads to a conservative estimate of LPI, whereas the Boulanger and Idriss [24] and Juang et al. [19] approaches lead to less conservative LPI estimates. Nevertheless, the estimates obtained by using the Boulanger and Idriss [24] and Juang et al. [19] methods are closer to those obtained from CPTu tests, at least for the CPTm-CPTu pairs compared herein.

The application of the corrections to the whole CPTm database revealed that if these corrections are applied together with the Robertson and Wride [16] LEP, then a significant increase in the LPI values occurs, thus highlighting a high or very high liquefaction severity in most of the considered territory. This fact appears to be in contrast with the historical evidence that has never reported relevant phenomena of liquefaction in Tuscany. The application of the corrections together with the Boulanger and Idriss [24] and Juang et al. [19] LEPs leads to a less pronounced increase in the LPI values and of the liquefaction severity class. It is therefore recommended to use these two LEPs for the CPTm interpretation in the study area.

Author Contributions: Conceptualization, methodology, data curation, supervision, and writing-original draft preparation, D.L.P.; conceptualization, methodology, writing-original draft preparation, and resources, C.M.; methodology, writing - original draft preparation, and software, S.S.; analysis of data and data curation, A.M. and M.B. All authors have read and agreed to the published version of the manuscript.

Funding: This research received no external funding.

Acknowledgments: The authors thank Pagani Geotechnical Equipment (Piacenza, Italy) for its technical support.

Conflicts of Interest: The authors declare no conflict of interest.

\section{References}

1. Kramer, S. Geotechnical Earthquake Engineering; Prentice Hall: Upper Saddle River, NJ, USA, 1996.

2. Caputo, R.; Papathanassiou, G. Brief communication "Ground failure and liquefaction phenomena triggered by the 20 May 2012 Emilia-Romagna (Northern Italy) earthquake: Case study of Sant'Agostino-San Carlo-Mirabello zone". Nat. Hazards Earth Syst. Sci. 2012, 12, 3177. [CrossRef]

3. Papathanassiou, G.; Caputo, R.; Rapti-Caputo, D. Liquefaction phenomena along the paleo-Reno River caused by the May 20, 2012, Emilia (northern Italy) earthquake. Ann. Geophys. 2012, 55. [CrossRef] 
4. Emergeo Working Group. Liquefaction phenomena associated with the Emilia earthquake sequence of May-June 2012 (Northern Italy). Nat. Hazards Earth Syst. Sci. 2013, 13, 935-947. [CrossRef]

5. Lo Presti, D.C.F.; Sassu, M.; Luzi, L.; Pacor, F.; Castaldini, D.; Tosatti, G.; Meisina, C.; Zizioli, D.; Zucca, F.; Rossi, G.; et al. A report on the 2012 seismic sequence in Emilia (Northern Italy). In Proceedings of the Seventh International Conference on case Histories in Geotechnical Engineering, Chicago, IL, USA, 29 April-4 May 2013.

6. Vannucchi, G.; Crespellani, T.; Facciorusso, J.; Ghinelli, A.; Madiai, C.; Puliti, A.; Renzi, S. Soil liquefaction phenomena observed in recent seismic events in Emilia-Romagna Region, Italy. Int. J. Earthq. Eng. 2012, 2, 20-29.

7. Lombardi, D.; Bhattacharya, S. Liquefaction of soil in the Emilia-Romagna region after the 2012 Northern Italy earthquake sequence. Nat. Hazards 2014, 73, 1749-1770. [CrossRef]

8. Papathanassiou, G.; Mantovani, A.; Tarabusi, G.; Rapti, D.; Caputo, R. Assessment of liquefaction potential for two liquefaction prone areas considering the May 20, 2012 Emilia (Italy) earthquake. Eng. Geol. 2015, 189, 1-16. [CrossRef]

9. Cubrinovski, M.; Bradley, B.; Wotherspoon, L.; Green, R.; Bray, J.; Wood, C.; Taylor, M. Geotechnical aspects of the 22 February 2011 Christchurch earthquake. Bull. N. Z. Soc. Earthq. Eng. 2011, 44, 205-226. [CrossRef]

10. Bray, J.D.; Zupan, J.D.; Cubrinovski, M.; Taylor, M. CPT-based liquefaction assessments in Christchurch, New Zealand. In Proceedings of the Papers of the 3rd International Symposium on Cone Penetration Testing, Las Vegas, NV, USA, 12-14 May 2014.

11. Maurer, B.W.; Green, R.A.; Cubrinovski, M.; Bradley, B.A. Evaluation of the liquefaction potential index for assessing liquefaction hazard in Christchurch, New Zealand. J. Geotech. Geoenviron. Eng. 2014, 140, 04014032. [CrossRef]

12. Maurer, B.W.; Green, R.A.; Cubrinovski, M.; Bradley, B.A. Assessment of CPT-based methods for liquefaction evaluation in a liquefaction potential index framework. Géotechnique 2015, 65, 328-336. [CrossRef]

13. Khoshnevisan, S.; Juang, H.; Zhou, Y.G.; Gong, W. Probabilistic assessment of liquefaction-induced lateral spreads using CPT-Focusing on the 2010-2011 Canterbury earthquake sequence. Eng. Geol. 2015, 192, 113-128. [CrossRef]

14. Cetin, K.O.; Seed, R.B.; Der Kiureghian, A.; Tokimatsu, K.; Harder Jr, L.F.; Kayen, R.E.; Moss, R.E. Standard penetration test-based probabilistic and deterministic assessment of seismic soil liquefaction potential. J. Geotech. Geoenviron. Eng. 2004, 130, 1314-1340. [CrossRef]

15. Seed, H.B.; Idriss, I.M. Simplified Procedure for Evaluating Soil Liquefaction Potential. J. Soil Mech. Found. Div. ASCE 1971, 97, 1249-1273.

16. Robertson, P.K.; Wride, C.E. Evaluating Cyclic Liquefaction Potential Using the Cone Penetration Test. Can. Geotech. J. 1998, 35, 442-459. [CrossRef]

17. Youd, T.L. Liquefaction resistance of soils: Summary report from the 1996 NCEER and 1998 NCEER/NSF workshops on evaluation of liquefaction resistance of soils. J. Geotech. Geoenviron. Eng. 2001, 127, 817-833. [CrossRef]

18. Juang, C.H.; Yuan, H.; Lee, D.H.; Lin, P.S. Simplified cone penetration test-based method for evaluating liquefaction resistance of soils. J. Geotech. Geoenviron. Eng. 2003, 129, 66-80. [CrossRef]

19. Juang, C.H.; Fang, S.Y.; Khor, E.H. First-order reliability method for probabilistic liquefaction triggering analysis using CPT. J. Geotech. Geoenviron. Eng. 2006, 132, 337-350. [CrossRef]

20. Moss, R.E.; Seed, R.B.; Kayen, R.E.; Stewart, J.P.; Der Kiureghian, A.; Cetin, K.O. CPT-based probabilistic and deterministic assessment of in situ seismic soil liquefaction potential. J. Geotech. Geoenviron. Eng. 2006, 132, 1032-1051. [CrossRef]

21. Idriss, I.M.; Boulanger, R.W. Semi-empirical procedures for evaluating liquefaction potential during earthquakes. J. Soil Dyn. Earthq. Eng. 2006, 26, 115-130. [CrossRef]

22. Idriss, I.M.; Boulanger, R.W. Soil Liquefaction during Earthquakes; Earthquake Engineering Research Institute: Oakland, CA, USA, 2008.

23. Boulanger, R.W.; Idriss, I.M. CPT and SPT Based Liquefaction Triggering Procedures; Report No. UCD/CGM-14/01; Center for Geotechnical Modeling, Department of Civil and Environmental Engineering, University of California: Davis, CA, USA, 2014; p. 134.

24. Boulanger, R.W.; Idriss, I.M. CPT-based liquefaction triggering procedure. J. Geotech. Geoenviron. Eng. 2016, 142, 04015065. [CrossRef] 
25. Robertson, P.K.; Campanella, R.G. Liquefaction potential of sands using the cone penetration test. J. Geotech. Div. ASCE 1985, 22, 277-286.

26. Yuan, H.; Yang, S.H.; Andrus, R.D.; Juang, C.H. Liquefaction-induced ground failure: A study of the Chi-Chi earthquake cases. Eng. Geol. 2004, 71, 141-155. [CrossRef]

27. Kayabali, K. Soil liquefaction evaluation using shear wave velocity. Eng. Geol. 1996, 44, 121-127. [CrossRef]

28. Andrus, R.D.; Stokoe, K.H. Liquefaction Resistance of Soils from Shear-Wave Velocity. J. Geotech. Geoenviron. Eng. 2000, 126, 1015-1025. [CrossRef]

29. Vaid, Y.P.; Hughes, J.M.; Byrne, P.M. Dilation Angle and Liquefaction Potential. J. Geotech. Eng. Div. 1981, 107, 1003-1008.

30. Robertson, P.K.; Campanella, R.G. Estimating liquefaction potential of sands using the flat plate dilatometer. Geotech. Test. J. 1986, 9, 38-40.

31. Tsai, P.H.; Lee, D.H.; Kung, G.T.C.; Juang, C.H. Simplified DMT-based methods for evaluating liquefaction resistance of soils. Eng. Geol. 2009, 103, 13-22. [CrossRef]

32. Iwasaki, T.; Tokida, K.; Tatsuko, F.; Yasuda, S. A practical method for assessing soil liquefaction potential based on case studies at various sites in Japan. In Proceedings of the 2nd International Conference on Microzonation for Safer Construction-Research and Application, San Francisco, CA, USA, 26 November-1 December 1978; Volume 2, pp. 885-896.

33. Tonkin and Taylor. Liquefaction Vulnerability Study; Tonkin e Taylor Ltd.: Auckland, New Zealand, 2013.

34. Sonmez, H. Modification of the liquefaction potential index and liquefaction susceptibility mapping for a liquefaction-prone area (Inegol, Turkey). Environ. Geol. 2003, 44, 862-871. [CrossRef]

35. Mayne, P.W. Synthesis 368: Cone Penetration Testing. NCHRP; Transportation Research Board, National Academy Press: Washington, DC, USA, 2007.

36. Boulanger, R.W.; DeJong, J.T. Inverse filtering procedure to correct cone penetration data for thin-layer and transition effects. In Proceedings of the Cone Penetration Testing 2018, Delft, The Netherlands, 21-22 June 2018; pp. 25-44.

37. Robertson, P.K.; Campanella, R.G.; Gillespie, D.; Greig, J. Use of piezometer cone data. In Use of in Situ Tests in Geotechnical Engineering; ASCE: Reston, VA, USA, 1986; pp. 1263-1280.

38. Robertson, P.K. Soil Classification Using the Cone Penetration Test. Can. Geotech. J. 1990, 27, 151-158. [CrossRef]

39. Robertson, P.K. Interpretation of cone penetration tests-A unified approach. Can. Geotech. J. 2009, 46, 1337-1355. [CrossRef]

40. Lo Presti, D.; Meisina, C.; Squeglia, N. Use of cone penetration tests for soil profiling. Ital. Geotech. J. 2009, 2, 9-33.

41. Meisina, C.; Persichillo, M.G.; Francesconi, M.; Creatini, M.; Lo Presti, D.C. Differences between mechanical and electrical cone penetration test in the liquefaction hazard assessment and soil profile reconstruction. In Proceedings of the ICCE International Conference of Civil Engineering, Tirana, Albania, 12-14 October 2017; pp. 95-105.

42. Meisina, C.; Stacul, S.; Lo Presti, D. Empirical correlations to improve the use of mechanical CPT in the liquefaction potential evaluation and soil profile reconstruction. In Proceedings of the 4th International Symposium on Cone Penetration Testing, CPT'18, Delft, The Netherlands, 21-22 June 2018; p. 435.

43. Lo Presti, D.; Giusti, I.; Cosanti, B.; Squeglia, N.; Pagani, E. Interpretation of CPTu in "unusual" soils. Riv. Ital. Geotec. 2016, 4, 25-44.

44. Regione Emilia Romagna (Italy). La Banca Dati Geognostica. 2011. Available online: http://ambiente. regione.emilia-romagna.it/geologia/cartografia/webgis-banchedati/banca-dati-geognostica (accessed on 3 February 2020).

45. Regione Toscana. Geoscopio: Geological Database. 2019. Available online: http://www502.regione.toscana. it/geoscopio/geologia.html (accessed on 3 February 2020).

46. NTC. Norme Tecniche per le Costruzioni 2018. Aggiornamento delle 'Norme tecniche per le costruzioni'. Gazzetta Ufficiale Serie Generale n.42 del 20-02-2018-Suppl. Ordinario n. 8. Italian Building Code (in Italian). 2018. Available online: https://www.gazzettaufficiale.it/eli/id/2018/2/20/18A00716/sg (accessed on 3 February 2020).

47. Galli, P.; Meloni, F. Liquefazione Storica. Un catalogo nazionale. Quat. Ital. J. Quat. Sci. 1993, 6, 271-292. 
48. Groholski, D.R.; Hashash, Y.M.; Kim, B.; Musgrove, M.; Harmon, J.; Stewart, J.P. Simplified model for small-strain nonlinearity and strength in 1D seismic site response analysis. J. Geotech. Geoenviron. Eng. 2016, 142, 04016042. [CrossRef]

49. Angina, A.; Steri, A.; Stacul, S.; Lo Presti, D. Free-Field Seismic Response Analysis: The Piazza dei Miracoli in Pisa Case Study. Int. J. Geotech. Earthq. Eng. 2018, 9, 1-21. [CrossRef]

50. Fiorentino, G.; Nuti, C.; Squeglia, N.; Lavorato, D.; Stacul, S. One-dimensional nonlinear seismic response analysis using strength-controlled constitutive models: The case of the leaning tower of Pisa's subsoil. Geosciences 2018, 8, 228. [CrossRef]

51. Liao, S.S.C.; Whitman, R.V. Catalogue of Liquefaction and Non-Liquefaction Occurrences during Earthquakes; Res. Rep. Dept. of Civ. Engrg.; Massachusetts Institute of Technology: Cambridge, MA, USA, 1986.

52. Spallarossa, D.; Barani, S. Disaggregazione della pericolosità sismica in termini di MR- . Progetto DPC-INGV S1 Deliv. D14 2007.

53. Pagani Geotechnical Equipment. 2017. Available online: http://www.pagani-geotechnical.com (accessed on 3 February 2020).

54. Viggiani, C.; Pepe, M. Il Sottosuolo della Torre. In La Torre Restituita; Gli Studi e gli Interventi che Hanno Consentito la Stabilizzazione Della Torre di Pisa; Poligrafico dello Stato: Rome, Italy, 2005.

55. Squeglia, N.; Stacul, S.; Abed, A.A.; Benz, T.; Leoni, M. m-PISE: A novel numerical procedure for pile installation and soil extraction. Application to the case of Leaning Tower of Pisa. Comput. Geotech. 2018, 102, 206-215. [CrossRef]

56. Schmertmann, J.H. Guidelines for Cone Penetration Test. In Performance and Design; U.S. Department of Transportation: Washington, DC, USA, 1978.

57. Lo Presti, D.; Stacul, S.; Meisina, C.; Bordoni, M.; Bittelli, M. Preliminary Validation of a Novel Method for the Assessment of Effective Stress State in Partially Saturated Soils by Cone Penetration Tests. Geosciences 2018, 8, 30. [CrossRef]

(C) 2020 by the authors. Licensee MDPI, Basel, Switzerland. This article is an open access article distributed under the terms and conditions of the Creative Commons Attribution (CC BY) license (http://creativecommons.org/licenses/by/4.0/). 